\title{
WestVirginiaUniversity
}

THE RESEARCH REPOSITORY @ WVU

Graduate Theses, Dissertations, and Problem Reports

2011

\section{Scenic Design Process for The Compleat Female Stage Beauty}

Andrew K. Moeggenborg

West Virginia University

Follow this and additional works at: https://researchrepository.wvu.edu/etd

\section{Recommended Citation}

Moeggenborg, Andrew K., "Scenic Design Process for The Compleat Female Stage Beauty" (2011).

Graduate Theses, Dissertations, and Problem Reports. 2219.

https://researchrepository.wvu.edu/etd/2219

This Thesis is protected by copyright and/or related rights. It has been brought to you by the The Research Repository @ WVU with permission from the rights-holder(s). You are free to use this Thesis in any way that is permitted by the copyright and related rights legislation that applies to your use. For other uses you must obtain permission from the rights-holder(s) directly, unless additional rights are indicated by a Creative Commons license in the record and/ or on the work itself. This Thesis has been accepted for inclusion in WVU Graduate Theses, Dissertations, and Problem Reports collection by an authorized administrator of The Research Repository @ WVU. For more information, please contact researchrepository@mail.wvu.edu. 


\title{
Scenic Design Process \\ for The Compleat Female Stage Beauty
}

Andrew K. Moeggenborg

\author{
Thesis Submitted to the \\ College of Creative Arts \\ at West Virginia University \\ in partial fulfillment of the requirements \\ for the degree of
}

Master of Fine Arts

in

Theatre Design and Technology

\author{
James Dylan Held, Chair \\ William Winsor \\ Robert Klingelhoefer
}

Division of Theatre and Dance

\author{
Morgantown, West Virginia \\ 2011
}

Keywords: Compleat Female Stage Beauty, Charles II, Edward Kynaston, English Restoration, Scenic Design 


\section{ABSTRACT \\ Scenic design process for the Compleat Female Stage Beauty}

\section{Andrew K. Moeggenborg}

This document is an account of my scenic design process for The Compleat Female Stage Beauty at West Virginia University Division of Theatre and Dance in the Fall of 2010. This thesis will detail the design process from the initial reading of the script, through meetings with the director and fellow designers, and the process and challenges of constructing models, renderings and the final scenery for the production. 


\section{Table of Contents}

Abstract__ ii

Table of Contents__ iii

Index of Images___ iv

Introduction___ 1

First Reading of the Script____ 1

First Production Meeting___ 3

Summer and Changes to Design Ideas___ 6

First White Models___ 7

Early Meeting of the Year____ 9

Final White Model__ 10

Image and Texture Research___ 12

Final Design Meeting___ 19

Final Budget Meeting___ 22

Construction and Painting ___ 23

Load-In__ 30

Technical Rehearsals___ 34

Dress Rehearsals__ 36

Preview Performance ___ 37

Evaluation__ 38

Conclusion__ 40

Works Cited__ 42

Gallery of Research Images___ 43 


\section{Index of Images}

Figure 1: Google Sketchup 7 Model

Figure 2: First 1/4" White Model

Figure 3: Second 1/4" White Model

Figure 4: Final 1/4" White Model

Figure 5: Banqueting House at Whitehall

Figure 6: Another view of the Banqueting House at Whitehall

Figure 7: Marble samples created with Adobe Photoshop

Figure 8: Engravings of the Covent Garden and Dorset Garden Theatres

Figure 9: Red Drapery Panels

Figure 10: Offstage Panels

Figure 11: Exterior Panels

Figure 12: Panels of Charles II Court

Figure 13: Final 1/4" Scenic Model

Figure 14: Final Ground Plan Presented to Benjamin Lauer

Figure 15:Front Elevation and Centerline Section Presented to Claire Phelps and Benjamin Lauer

Figure 16: First Attempt at Marble

Figure 17: Completed Dark Marble on the Upstage Platform

Figure 18: Completed Dark Marble on the Downstage Platform

Figure 19: Progress on the Drapery Panels

Figure 20: Texture on Stone Panels before Mortar Lines

Figure 21: Stone Panels on paint frame

Figure 22: Base color on floor with plank lines being added

Figure 23: Floor after first grain wash

Figure 24: Completed Floor with polyurethane top coat

Figure 25: Completed set with fabric reveals visible on panels

Figure 26: Ben in Tavern Setting

Figure 27: Bed in Theatrical Setting

Figure 28: Furniture in the backstage setting

Figure 29: Third bench when set for handicapped seating 


\section{$\underline{\text { Introduction }}$}

In the Spring of 2010 I was assigned The Compleat Female Stage Beauty as my thesis design for the Division of Theatre and Dance at West Virginia University. The director of this production was Professor Phillip Beck with Costume design by Hannah Wold, with lighting design by Clair Phelps, sound design by Alan McEwen, and technical direction by Benjamin Lauer. The production was scheduled to open in November, 2010 in the Gladys B. Davis Theatre at the West Virginia University Creative Arts Center.

The Design process for this project began in May, 2010 when initial meetings with the director were held, followed by additional design meetings in August with the other designers and individually with the director. The results of these initial meetings concluded with the finished production in November. This thesis is an evaluation of the design process from initial discussions of the script, through conceptual research as well as the construction of the scenery and the overall completed design.

\section{First Reading of the Script}

I was first given a script of the Compleat Female Stage Beauty in April, 2010 soon after being assigned to the project for my thesis design with the Division of Theatre and Dance. As with the first reading of any script as a designer, I was concerned less with scenery than with absorbing the story and characters that the author had created. I was immediately struck by several key elements of the script:

Edward Kynaston, the play's protagonist, was a famous actor in seventeenth century England who made his fame by portraying women on stage. The script follows him on a voyage of discovery that sees him thrown out of work by new laws which ban males from playing women, and how he eventually finds his place in the new theatrical world. The Compleat Female 
Stage Beauty is an often touching, and sometimes shocking depiction of English society during the Restoration of Charles II. Being interested in the history of the period leading up to the English Civil war and its aftermath I was very interested to see how the famous faces of history were to be portrayed in the script, specifically Charles II and I felt that they worked quite well in the story. Charles II and Nell Gwyn were particularly entertaining as was the character of Thomas Killegrew. What worried me most about the script were certain elements of the story, especially the amount of risqué behavior between Kynaston and his lover Lord Villiers, as well as two scenes of female nudity. Though not the worry of a scenic designer I none-the-less wondered how such a story would be received by student audiences.

Upon the second reading, challenges of the scenery came into sharper focus. The Compleat Female Stage Beauty is a modern work of drama in that it breaks its action evenly into two acts split by an intermission. The real challenge of this particular script was that it seemed to be written more as a screenplay than as a stage script. Though this made for a very fast first read through, it also caused some anxiety in how to design it for the stage. The script is broken into twenty-one scenes, a daunting task for any designer but it was the speed that scenes had to flow was a cause for great concern. The main character, Edward Kynaston, travels from his theatre to his dressing room, to the court of the king, to parks and taverns, and even coffee houses and shabby hotels. Settings for the piece ranged from the very lap of luxury in court to the most informal and dirty places in seventeenth century society. After re-reading the script I discovered that nineteen settings were needed and that some scenes required fast changes to different settings in the same scene. This cinematic structure necessitated very sudden scene shifts, some of which had to occur literally on top of the performers. After this second reading of the script I began thinking of different scenic options that would fit the plays structure. 
Based on experience in past designs I knew that in order to make a stage picture visually appealing, different levels would be necessary. I was also aware that to create a completely different setting for each scene would be impractical, so I determined that a unit setting onto which different pieces of furniture and lighting effects could be applied was the ideal choice. Unfortunately there were scenic elements in the script which could not be achieved given the resources and safety needs of the Division of Theatre and Dance, namely flying actors on and off stage as Nell Gwyn does in the first act of the script. I also noticed that most of the major dramatic scenes in the play took place around a bed, one onstage at Killegrew's theatre and the other in a tavern. It was based on these notes taken from the first readings of the script that I prepared questions to ask Professor Phil Beck, the director of the play. The first and most prominent question that went through my mind for Professor Beck was how he wished to tackle the numerous settings. Was he in favor of creating nineteen separate settings or did he favor a more stylistic approach which would include suggestions of large settings by adding perhaps a few furniture pieces to a unit set? To deal with the number of scene shifts necessitated by the script would he wish to see stagehands moving scenery or would he like to see the crew in costume or even have the actors themselves change scenic elements as they entered or exited the stage? Chief amongst concerns for the scenery dealt with the spectacle detailed in the script, the seamless changes and the flying performers, as well as any special considerations Professor Beck would like to avoid or highlight in the more risqué moments in the play?

\section{First Production Meeting}

Armed with questions I had compiled for Professor Beck and other members of the production team, an initial design meeting was held on May 10, 2010. Attending this meeting were the director, the other designers, the stage manager, production manager, Technical 
director, and Robert Klingelhoefer; properties and supervisor to the set designer, Mary McClung; costume supervisor and I. This meeting was held as a basic introduction to the design process where Mr. Beck could give his initial thoughts on the show and on what he believed that he needed from each designer. Before speaking with each designer individually Mr. Beck shared his thoughts on what the world of the script looked like conceptually. Since the plot of The Compleat Female Stage Beauty takes place immediately after the Restoration of Charles II to the English throne, Mr. Beck wanted the scenery, lighting and costumes to reflect the very ornate and gilded art of the time period. With regards to the theatre settings and costumes, Mr. Beck believed that the designers should somehow show that these theatres had literally just been reopened, that some pieces may still be dusty or worn in some way.

Professor Beck spoke briefly with each designer in turn and the following was decided with regards to the scenic design: Professor Beck shared my fears over the sheer number of scenic elements needed, though he left it to my discretion to determine different ways to tackle the problem. I suggested a unit setting with some moving elements, specifically hiding the bed that had to be used in multiple settings within or behind pieces of the set when not in use. One idea that came out of this discussion was the idea of a giant puzzle of scenery that could be reconfigured in different ways for different scenes. Professor Beck also requested that as much of the scenery as possible should be raised off the deck to illustrate the idea that the play is set on a stage within a stage. A final request regarding scenery was a very obvious one given a single unit set a sense of neutrality that would work with the costume and furniture pieces that would interact with it. The second big talking point of this initial meeting dealt with budgets and safety.

Shortly before the meeting on May 10th, I expressed my concerns regarding flying objects and people from the grid in the Davis Theatre with Professor Neuenschwander, the 
production manager and technical director for the Division of Theatre and Dance, who informed me of the difficulty but suggested investigating possibilities before the first meeting. The first concern brought up on May 10th was cost: flying an actress would involve equipment that the department did not own, and would also take up many resources in terms of labor and budget. A further problem with flying the character of Nell Gwyn from our grid was the fact that Nell in that particular point of the script was intended to be nude save for a shield carried in front of her. This fact was a particular safety issue for Mr. Neuenschwander as any flying actor or actress has to wear a special vest in order to prevent a detachment from cables. These factors combined with the fact that the total height of the grid in the Davis Theatre is only eighteen feet meant that the overall distance travelled by the actress would be very short and would force the actress to stay in one place once lowered due to the amount of safety equipment she would be wearing. To overcome this challenge I suggested that I create a staircase or ramp of some kind upstage to allow the actress to quickly appear for a grand entrance and all involved thought this would be an ideal solution. Upon completion of the meeting each department was informed of their budgets, Stage Beauty, was allocated $\$ 3,500$ for scenery and paint. It was at this point that I requested an individual meeting with Professor Beck before the university was closed for the summer in order to show him the first thumbnail sketches that I had come up with after reading the script.

The first thumbnail images of possible Compleat Female Stage Beauty configurations was drawn in a notebook shortly after my second reading of the script. There were four playing areas present in the set: one main raised platform that could act as a false stage and a large downstage playing area on the Davis Theatre stage floor, two different upstage platforms at higher levels than the false stage. Each area could represent a different setting and allow for scenery to be changed in one area while action took place in another. Professor Beck asked me to 
develop it further over the course of the summer and at this stage we also spoke of a false proscenium that could include design elements from the sixteenth century. During this meeting I proposed the idea of making the bed, used in multiple scenes, a permanent part of the scenery that could be hidden underneath one of the raised platforms and Professor Beck approved this approach. At this stage of the process, each designer was released for the summer after being informed that final scenic, costume, and lighting designs would be due September 10, 2010.

\section{Summer and Changes to Design Ideas}

As happy as I was with my initial sketches, as I further developed and drew more thumbnails I discovered several fundamental flaws with my initial approach to the scenery. Though having four playing areas was a distinct advantage to have for the play, I concluded the way in which they had been arranged would be impractical. The first thumbnail included two separate upstage platforms that were in no way connected, this would confine any action to a relatively small area in a far upstage corner of the

stage. This upstage

orientation would not only further distance the audience from the action but make the simple act of viewing the play more difficult as the lines of

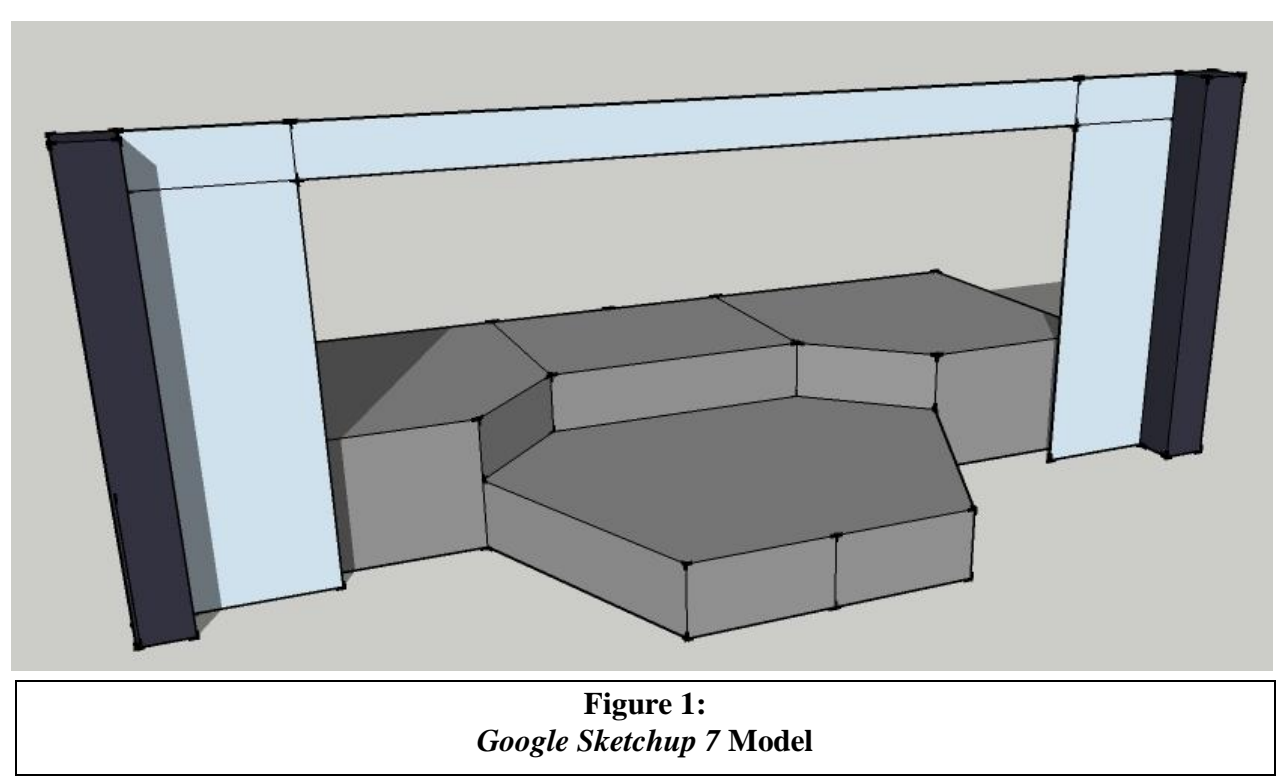
sight from the most extreme left or right sections of the audience impeded the view of most of the upstage platforms. Quickly the first thumbnails were discarded in favor of an orientation that 
still followed Mr. Beck's initial requests but shortened the distance between audience and performer.

I decided instead to adopt a three level set, the Davis Theatre floor would make up one level while a false stage, elevated roughly three feet, would make up the second. Replacing the two separate upper platforms would be one long platform that would be oriented immediately upstage of the second level. I discovered that an ideal place to set the all important bed was on the second level, by making the third and final level raised a sufficient height that the bed could be shifted underneath the upper level, thus allowing the second level to play multiple scenes. In order to make the shifting of the bed work, the front face of the upper platform could not be a solid piece of lumber, but would need to be a softer material that could be moved aside when needed and not show seams when closed. I decided that to include this fabric facing on only one section of the set would seem out of place, so I decided that by including it in all facing on the set would give a more uniform look and allow for even more scenic or prop elements to be hidden in different parts of the set. Upon this reworking of my ideas for the scenery I decided to construct a digital model using the Google Sketchup 7 program, to develop spatial relationships within the Davis Theatre without having to physically construct a model. I decided that when I arrived back at West Virginia University in early August I would construct white models based on my summer ideas and then show them to Mr. Beck and the remainder of the design team.

\section{First White Models}

Upon returning to West Virginia University I consolidated my ideas and began work on the first of my 1/4" scale white models for The Compleat Female Stage Beauty. Work on this included the conclusions I had come to over the summer with my thumbnail sketches: a three level set with a false proscenium. I decided to place the false proscenium against the pillars 
located on either side of the Davis Theatre stage, which extended five feet into the main stage space from each pillar. The false proscenium did not have a header piece to connect the two

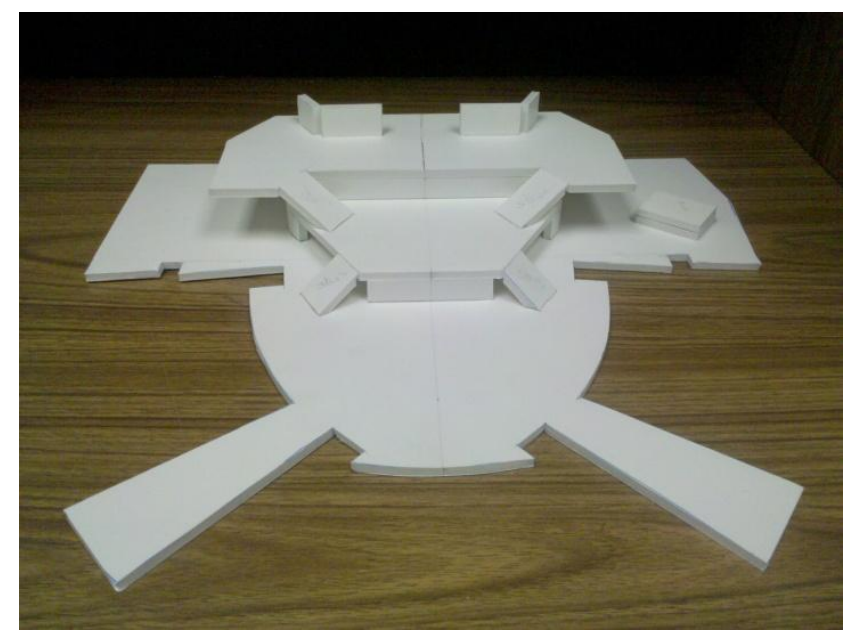

Figure 2

First 1/4"' White Model pieces against the pillars on either side; I decided that by adding one, too many lighting positions would be lost particularly on the upper levels. The first level of the scenery was elevated three feet above the stage floor with the second level elevated another three feet to for the bed. At the most upstage part of the upper platform I installed two low garden walls that, depending on treatment, could double for the court of Charles II as well as scenes that took place in parks around London.

All reservations I had about the first white model concerned practical and not artistic concerns, specifically whether the overall height of the scenery would be too tall to allow for proper lighting, and if the second tier would need to be larger. Though I was very pleased with this first model, a direct result of the conclusions I had arrived at over the summer, I took note of each potential challenge to discuss with Mr. Beck at a later time.

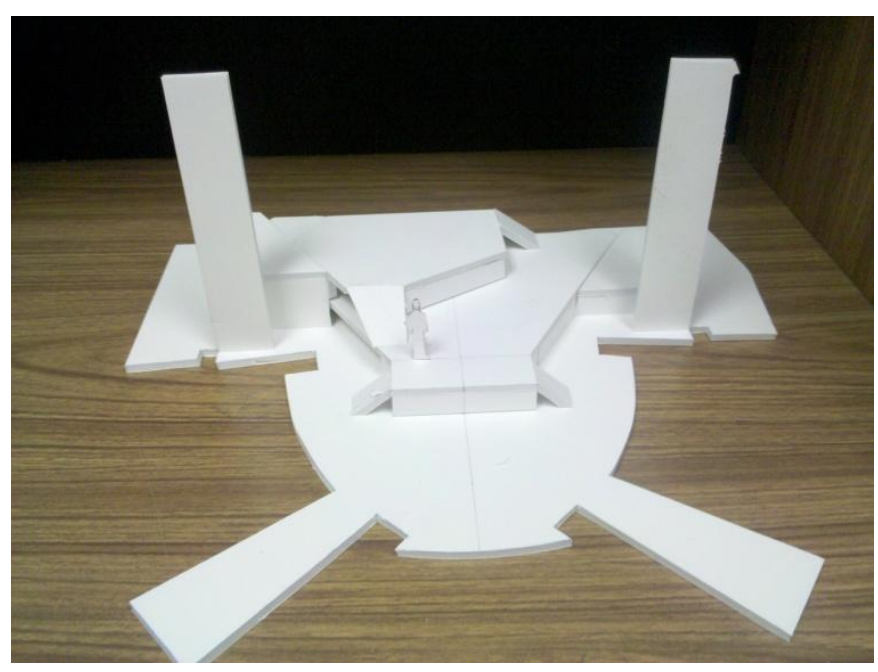

Figure 3

Second 1/4" White Model

For the second 1/4" white model, I decided to attempt an asymmetrical set, far removed from the first model. The second level of this set was essentially unchanged save for an extra 
four feet added to the tip of the platform to allow for more playing space. I also changed the top level by placing it at an extreme angle off to the stage right side of the stage. Though this was a vastly different approach, I had many reservations about this second design. I believed that this second model was far too jarring to the senses and would be more suitable to a non-realistic play, furthermore upon placing the bed onto the second platform, I determined that there was very little room for actors to move around it, or to be practical onstage. Sight line problems were far more apparent in this model but I decided that I would show both models in the first production meeting of the semester.

\section{Early Meetings of the Year}

On August 20, 2010 the entire design team met for the first time in four months. This meeting was not for final designs but for each designer to display their progress. I presented both of my white models in this meeting and Professor Beck preferred my first more symmetrical setting to the jarring asymmetrical one. It was in this meeting that the first real discussion of scenic shifts took place, Professor Beck and I believed it would be best if all furniture shifts were done by members of the cast, and the option of costumed crew members was given to costume designer Hannah Wold. Professor Beck also decided that he preferred the bed being placed on the Davis Theatre floor than on the second level. I welcomed this idea because it meant that the top level did not need to be so tall and that the actors would have far more space around the bed in which to walk.

Additionally the first thought of color treatments took place, particularly the discussion of color as it related to the curtains I planned on using as facing, since Hannah Wold was using many purple elements in her costumes, I decided that purple curtains might do a great deal to bring together scenic elements and costumes as a unifying color. As a group it was decided that 
something more would be needed to change scenery than simply having crew members shift furniture pieces, though no consensus was reached. Upon the completion of this meeting, I had many more options to consider in building a final white model.

\section{Final White Model}

For the final white model I decided to make more subtle changes than overt ones. I changed the shape of the second level slightly, but increased it in height to four feet above the Davis Theatre floor. Regarding the top level, since it was no longer necessary to hide the bed beneath it, I decided to decrease it in height to a mere eighteen inches above the second level and make the entire downstage border of the platform a staircase, which would match the royal settings in the court of Charles II by suggesting a large palace staircase. The one main change in the final white model of the set was the false proscenium.

Though it had been included in every incarnation of the scenery since the first thumbnail sketches, I determined that the false proscenium would not serve the purpose I had initially

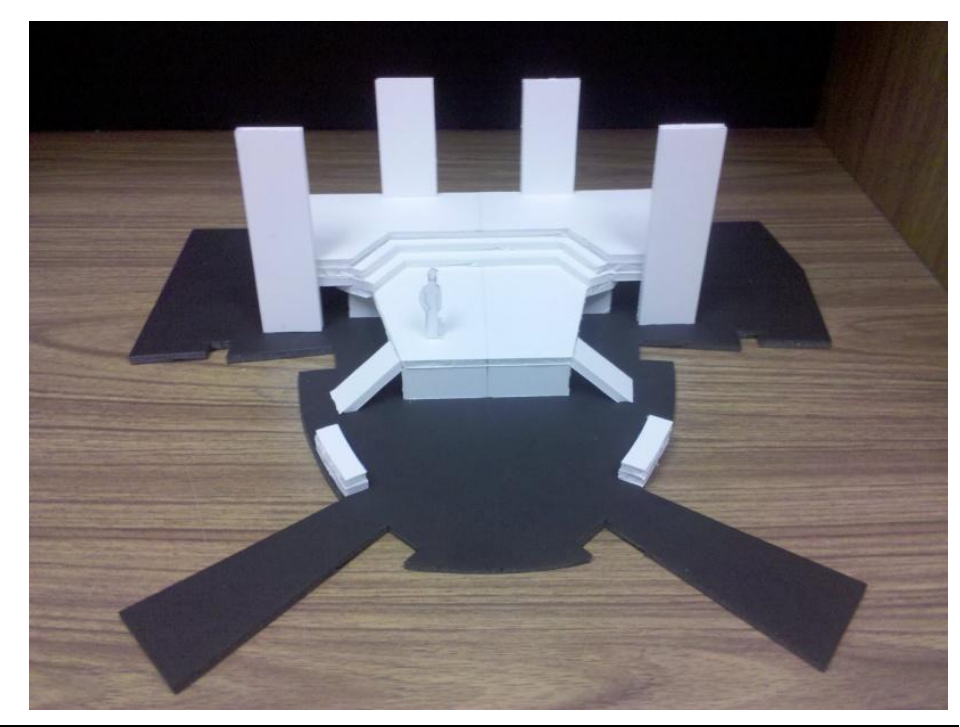

Figure 4

Final 1/4" White Model included it for and would instead look

like two very ornate walls placed at random on either side of the stage. It was during construction of this final white model that I found another use for wall flats flanking the stage, and if this solution worked it would solve the important problem of scenic shifts. In sixteenth century theatre a popular way for changing scenery was known as a drop and wing system, this system championed in Italy and later across Europe was a series of painted walls 
that would flank the stage parallel to the plaster line. I also knew from theatre history that a popular way of shifting these panels would be to build tracks in the floor to simply slide these walls on and off stage. Upon this realization I knew instantly that this would be the preferred method for changing scenery.

Though there are nineteen settings in the play, I discovered there were only four basic types of scenic locations: onstage, backstage, court, and standard city settings. I decided that four sets of panels would therefore be ideal for shifting between each setting and more importantly could be done with no crew being visible onstage. Upon placing these panels in the model however, I determined that there was now a very large empty void upstage of the main platforms, I decided that by adding two more shifting panels upstage of the top level and closer to center would create a much more attractive stage picture. It was this white model that I brought to Professor Beck.

Professor Beck liked the changes I had made to this final white model, and gave me approval to begin choosing treatments and colors for the scenery. We also discussed the type of furniture that would be necessary for each setting and determined that a nondescript set of furniture, built to fit the period of the English restoration could work for all necessary settings. Also discussed at this meeting was exactly where on the set specific scenes should take place, specifically scenes taking place on a stage. Though the bed had been moved downstage to be closer to the audience, I suggested placing benches on either side of the stage so that Mr. Beck could include other cast members watching the plays. Since there are several scenes in which the audiences of London interact with the main characters as they perform, this was an ideal solution to the challenge. I also suggested that by placing chairs on the furthest downstage edge of the Davis Theatre stage, the climactic scene of the script during which a royal company witnesses a 
play could allow the very characters to be physically in the space to witness the action. At the conclusion of this meeting I was given permission to begin a final search for colors and treatments, this is where the main part of my research into textures and the time period, took place.

\section{Image and Texture Research}

Up to this point in the process most of the work that went into the white models and ground plan dealt directly with practical concerns of moving actors and scenery. However, vital aspects of the design still needed to be determined, such as colors, and textures, Professor Beck wished for the textures of the scenery to fit Restoration England as opposed to suggesting locales with more modern textures. To begin such research my first step was to make a list of books available at the WVU Libraries that dealt with architects and artists of the time period; I was specifically interested in architect Christopher

Wren and painter Peter Paul Rubens. I had prior knowledge of Wren and Rubens from Simon Schama's A History Of Britain documentary series as well as classes I had taken at WVU the previous year. Since both men were very active in England either during the Restoration or immediately before I determined these men would be a good place to begin textural research.

Specifically I looked for buildings and palaces designed by Wren, but I was disappointed to find that most books written about his work

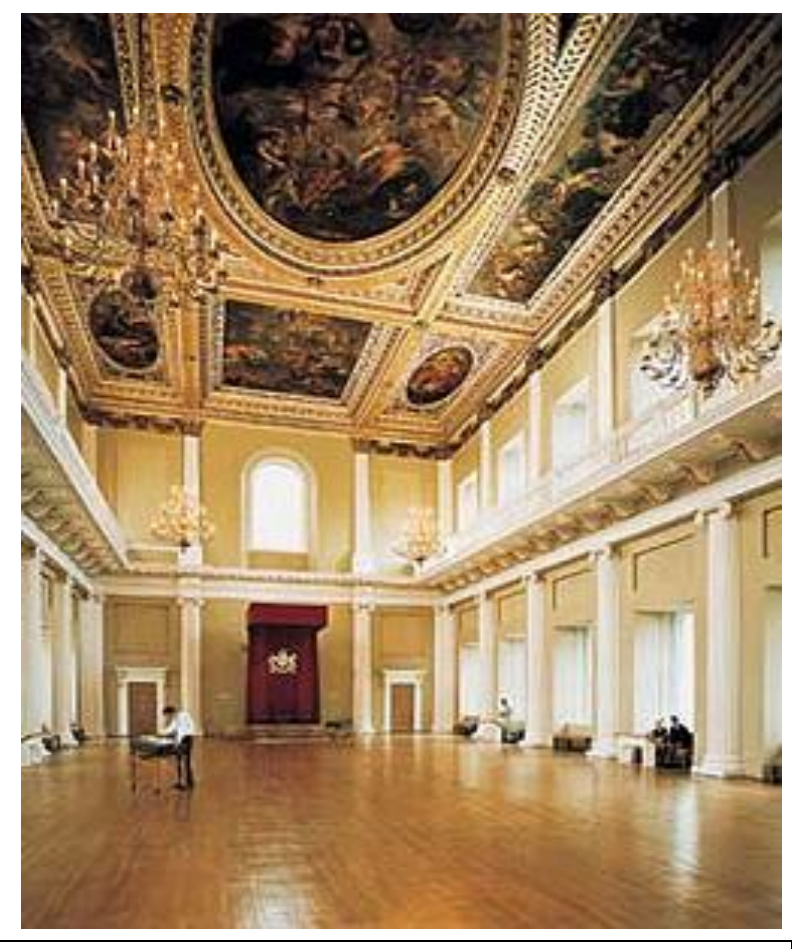

Figure 5 Banqueting House in Whitehall http://www.londonpass.com/attBanquetingHouse.asp 
concerned the construction of Saint Paul's Cathedral built after the great fire of London in 1666. Though this would have been the correct time period, taking textures from a cathedral I felt would add too many religious tones to the scenery. Furthermore, Wren designed very few royal residences which would not fit with Professor Beck's vision of the play. While looking for books of Wren I also found a great deal of material on Inigo Jones, another architect of the time period that I had initially discarded because he was more active in the court of Charles I than the court of Charles II. Jones' most famous structure and one that is mentioned specifically in relation to Peter Paul Rubens in A History of Britain is the Banqueting House in the Palace of Whitehall.

As with its architect, I initially discarded using any elements from the Banqueting house due to the period it was designed in, but I was still drawn to many elements that I felt could fit very well with The Compleat Female Stage Beauty. The Banqueting house has a very distinct exterior facade that includes many striking elements of decor that could be included on scenic panels for exterior and neutral settings. Arguably the most beautiful part of the structure is the banquet hall itself, a large room flanked by columns and windows which included golden chandeliers, a hardwood floor and a ceiling painted by Rubens. The paintings in the Banqueting ceiling were meant to glorify the reign of James I and his family the Stuarts; the painting was commissioned by James' son Charles I. Upon more research on the Banqueting house I

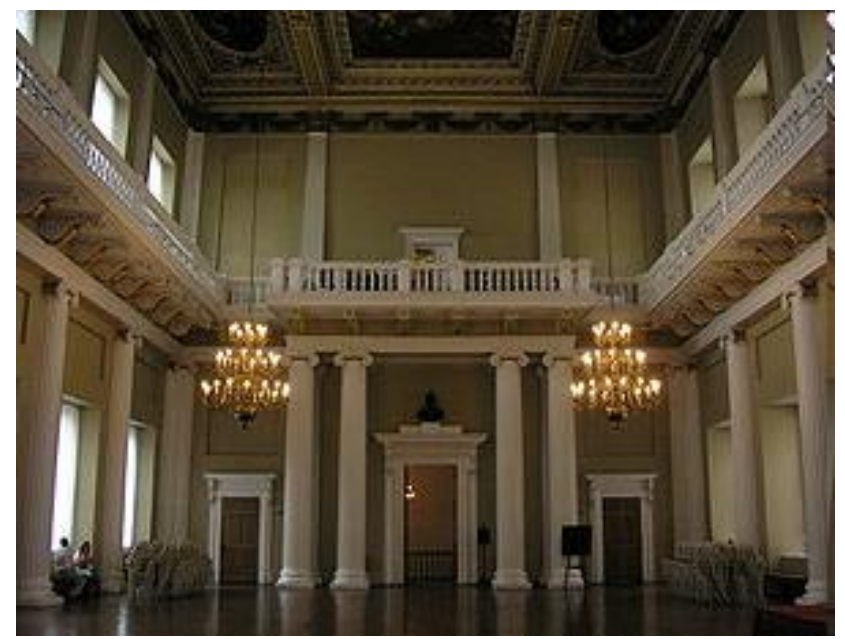
discovered that not only did Charles I use it for holding court and banquets but also court masques, the exterior was also the site on which Charles I was beheaded after the English Civil Wars. Clearly the building had great historical significance, but what moved 
it to the forefront of my research was the fact that after the restoration Charles II also used the structure his father built for, among other things, the staging of private plays. This solidified in my mind the wish to use the Banqueting House in Whitehall as the basis for my color and textural research.

Though the interiors of the Banqueting house have a great deal of regal and gilded textures what it did lack was a great deal of variety. Upon meeting with Professor Beck he requested that I use textures that would appear royal but also offer variation, for instance he did not want the entire set to have a wood floor or for every panel to be a reproduction of a Rubens painting. One texture that did intrigue both of us was marble, a texture long associated with the rich and royal, a combination of marble with the rich hard wood would accent the set well and offer Mr. Beck the variation he was looking for. I decided to search for more specific marble and hard wood textures, and to pull more elements from the interior and exterior of the Banqueting House to show to Mr. Beck before attempting my final renderings and models.

I first began the search for marble textures online, with different marble and granite suppliers, I also looked in the Surfaces reference book. I decided that two colors of marble would be necessary for the upper platforms of the set, a solid dark color would coat them, but upon

experimentation in Adobe Photoshop I decided that to use a lighter color as a border would be a viable way of creating a more unified look. Using the images I had found of marble I made a slide show displaying possible combinations to show

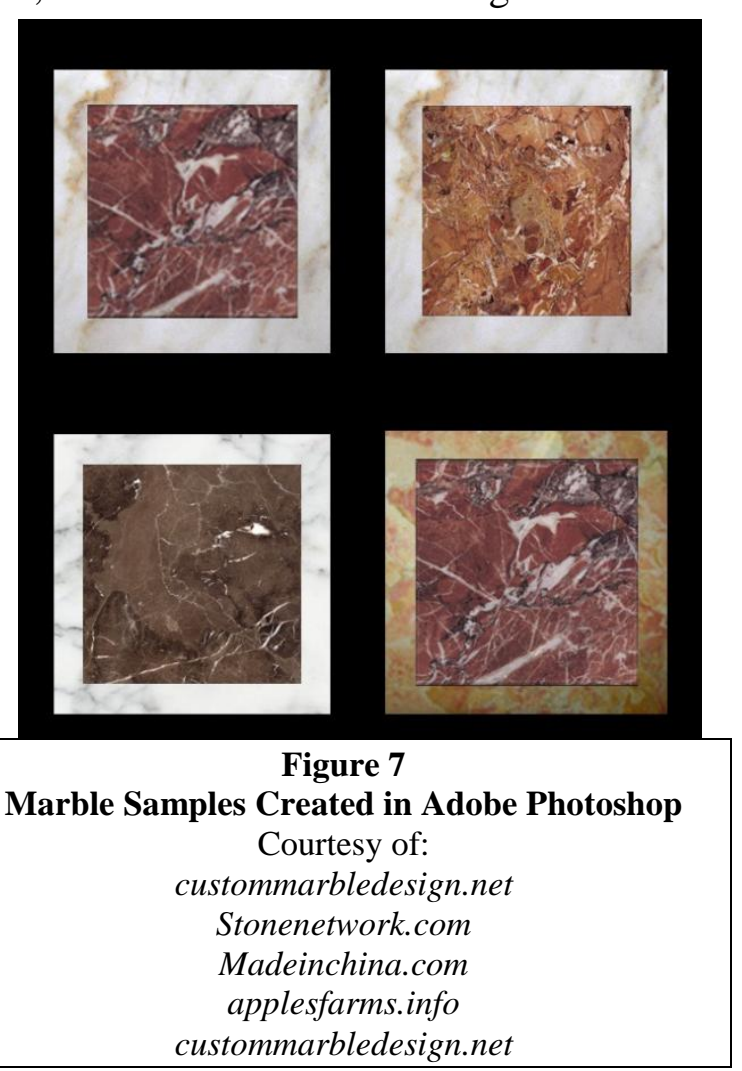


Professor Beck and I also found more images of the floor of the Banqueting House for research on its hard wood floor, but in the end I looked to the Surfaces book to find a type of wood tone that best matched what I saw in the photographs. Upon showing this research to Professor Beck he and I chose the color combination that we thought would work best, a red and brown marble with a white accent, as it would be bright and cheerful as well as regal. In this meeting Professor Beck made another very helpful suggestion, that the marble should be very theatrical in appearance; though he approved of the colors I had found, he did not want it necessarily to be too realistic. Using the example of marble textures painted on the reconstructed Globe Theatre in England as a guide I agreed with this conclusion because not only would it better fit the theatrical nature of the show but it would also be easier to accurately duplicate in the final set.
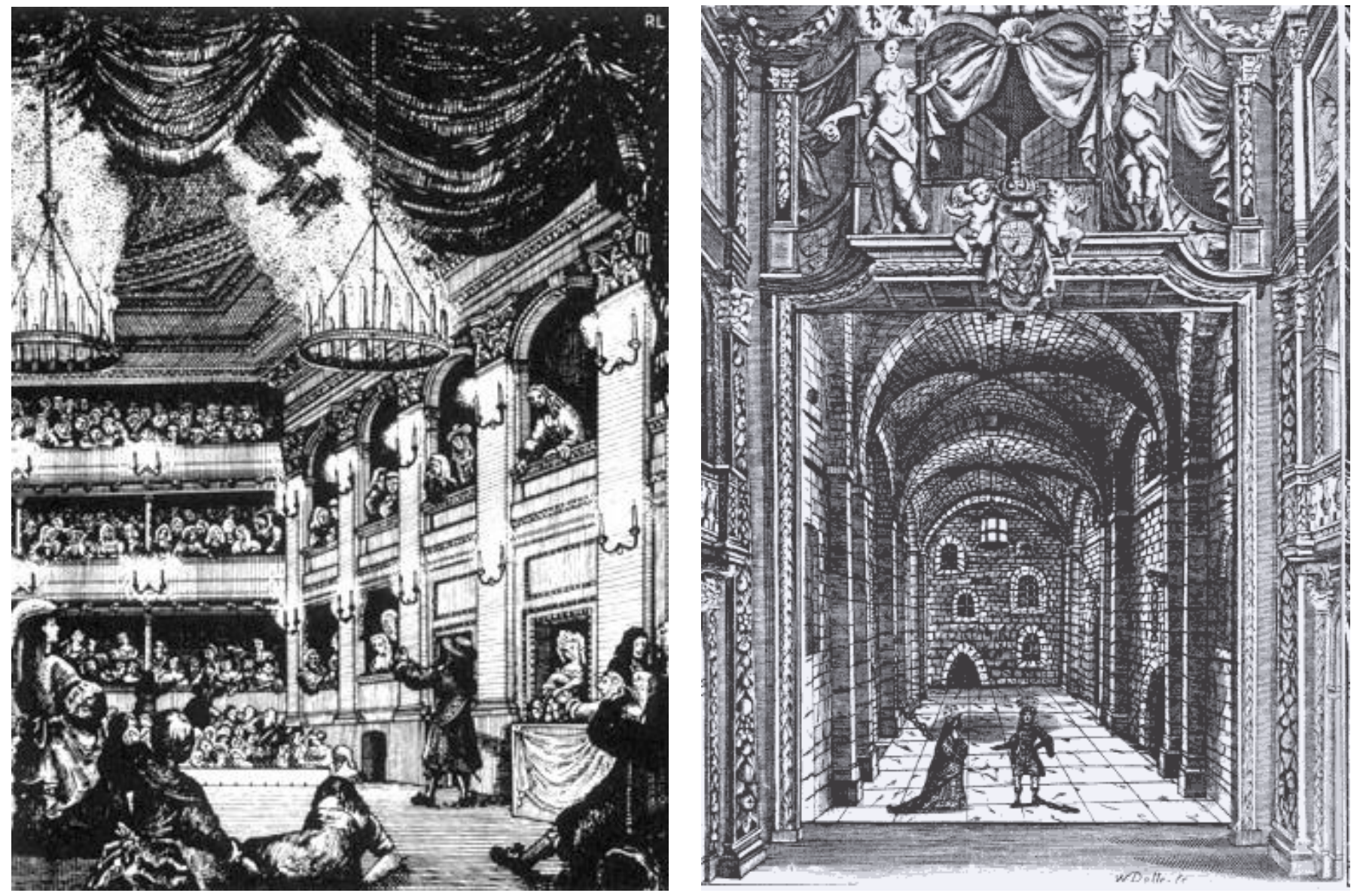

Figure 8:

Engravings of the Covent Garden and Dorset Garden Theatres michaelbryson.net and absoluteastronomy.com 
When discussing panels I made a list for Professor Beck of all the necessary settings. I determined that there were four general locations in the play, the first being onstage when characters are performing their plays, the second when the characters were supposed to be backstage, the third being the court of Charles II and the fourth a more neutral setting which could double as a park, tavern, or coffee house. To create an onstage setting I wanted to create a set of panels that would act much like the original idea of a false

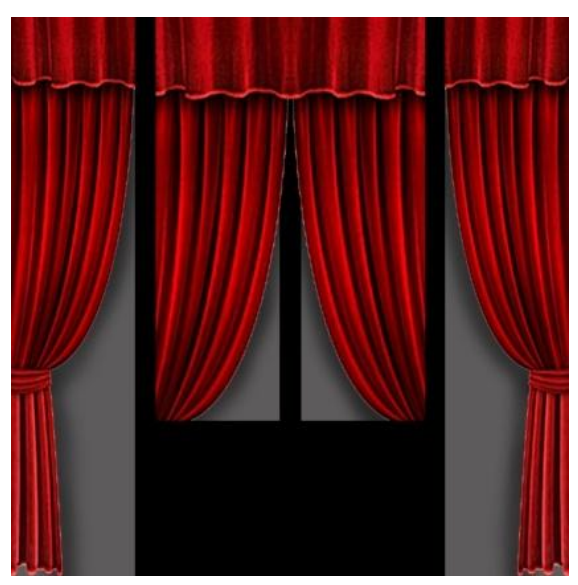

Figure 10 Red Drapery Panels Photoshop Rendering proscenium, similar images of the Covent Garden and Dorset Garden theatres. Upon further discussion with Mr. Beck we decided that this idea of a grand false proscenium would confuse the audience particularly as it would be too close in appearance to the decor that would appear in

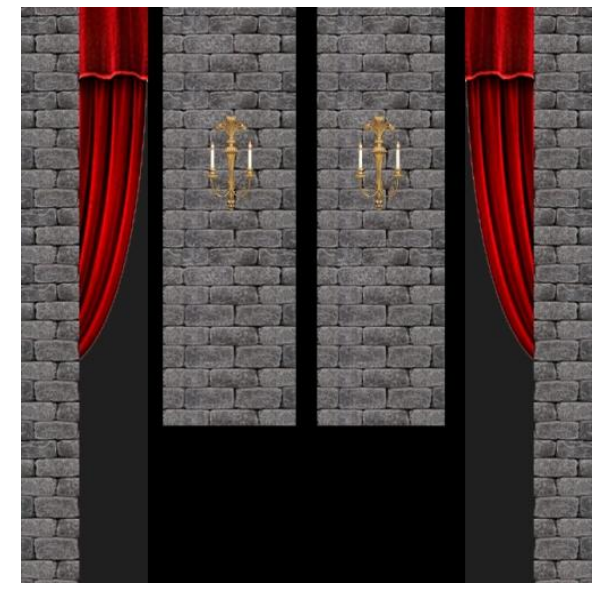

Figure 9

Offstage Panels Photoshop Rendering
Charles II's court. This was initially a challenging dilemma how to differentiate onstage and backstage when the characters would not be exiting the stage to allow for a full scenic and furniture shift. Finally I arrived at a satisfactory way to solve this challenge, a set of panels displaying drapery, specifically red drapery that is so often associated with theatre for the onstage setting. For the backstage setting I decided that to paint the curtains as if they were being viewed from behind would be

best. The two upstage panels would be painted as a stone wall, and the downstage panels would display curtains that were partially obscured by the same stone walls. I believed that this idea 
could be the answer to the question of how to show that the characters are still in a theatre but are no longer in view of the their audience.

For the set of panels that needed to display the court of Charles II, I decided on a very simple arrangement. Columns from the interior of the Banqueting house, two to a panel would surround the space, each capped with golden details and a background of purple would show the audience that the setting was now of a royal nature. Using the Banqueting house as a guide I added detail to the columns that would further display their royal nature - specifically details in the caps of the columns. The fourth and final set of panels proved to be more difficult; this was the setting that would acts as a backdrop for the tavern, the coffee house and the

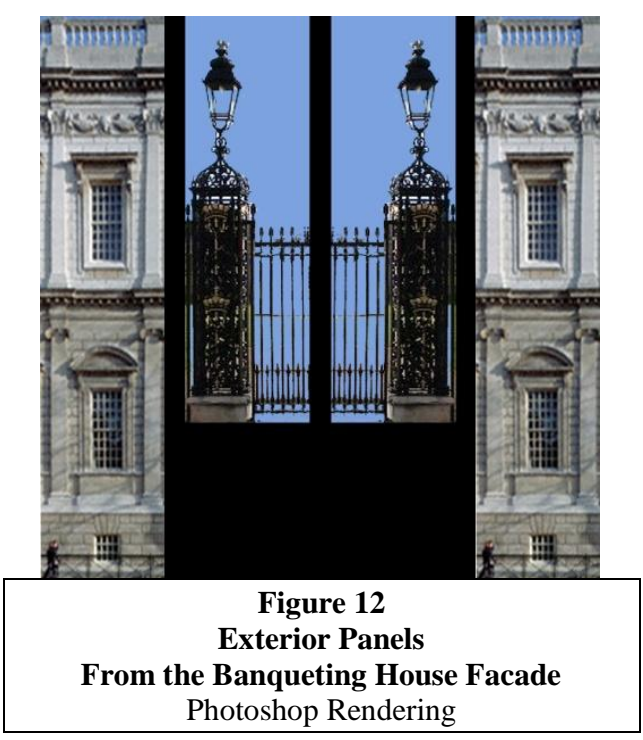
London park. Since Professor Beck was planning on using a different part of the stage for each scene it was essential that the panels have elements to match each scene. Again I decided to use the Banqueting house as a guide but instead of using the interior I used elements of the facade

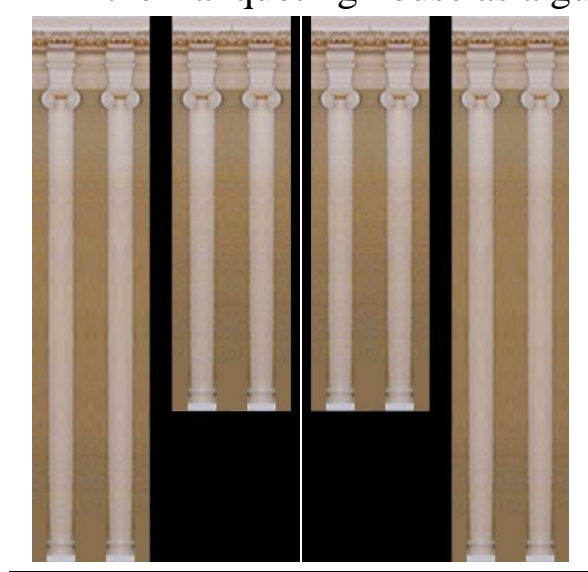

Figure 11

Panels for Charles II Court Photoshop Rendering and gardens for ideas. For the exterior setting I added the main gate which included elements that were usually associated with a public park - wrought iron fences and lamp posts being the primary elements. This would display a neutral setting but still fit within the world of Charles II as described by Professor Beck. For the downstage panels I took two vertical sections of the exterior facade designed by Inigo Jones, which included windows as well as stone

and brick work that could be used to suggest London street settings. 
It was with renderings of each of these ideas that I met with Professor Beck to discuss options. After I had finished showing each set of panels and proposed floor treatments, he gave me permission to begin work on a final model. This both surprised and elated me as I could now begin working on the final design. As each new element was approved, I informed the technical director of the production, Ben Lauer, to allow him a head start on planning the intricate workings of the sliding panels and bed frames. He expressed some concern over panels that had to move on and off stage as our department did not own the technology to do so. Upon being told his concerns my first step was to inform Professor Beck that the cost of the panels might force cutting down their number from four settings to three, but this was a decision that could not be made until the final budget was determined after the design was final. I also showed each rendering to the costume designer, Hannah Wold, who informed me that no colors or textures that I had chosen would clash with the colors she had chosen for costumes or makeup.

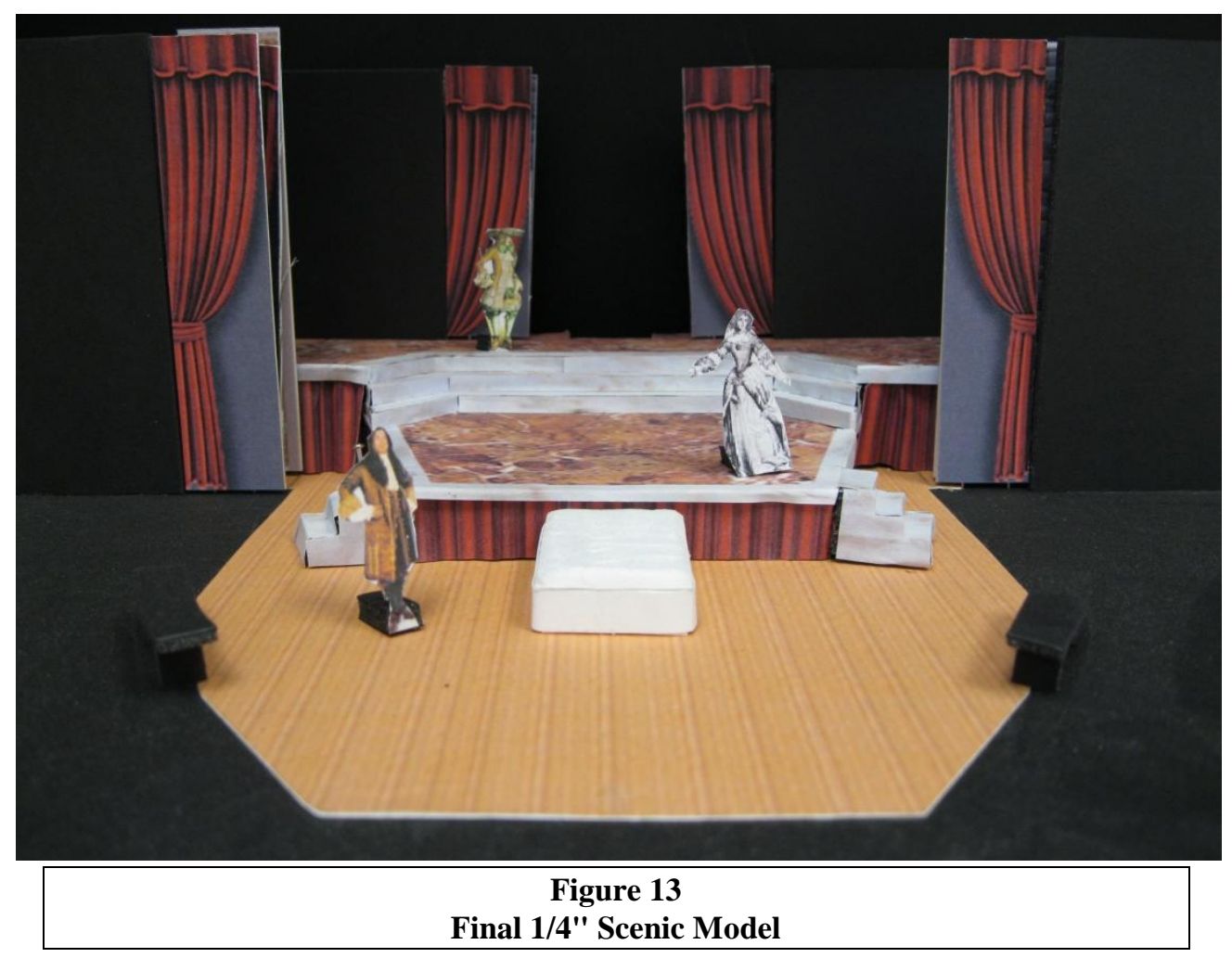




\section{Final Design Meeting}

On September 10, 2010 the designers of The Compleat Female Stage Beauty presented their final designs. I had prepared a final 1/4" model which included all completed textures and colors as well as all four sets of panels to show to the rest of the team. I also brought with me several research images including the Banqueting House of Whitehall. Professor Beck as well as the rest of the design team thanked me for my preparation, and then raised final concerns over the design going into the budgeting period.

Professor Beck and I had decided to place the bed downstage of the second level so that it could slide underneath it when not needed. Given this configuration Professor Klingelhoefer raised the point that the curtains would need to part to allow for the bed to move, a point that I had already considered but had forgotten to include in my presentation. Professor Neuenschwander raised the point that if I made some changes to the upstage sections of my ground plan I would negate the need to create two different sizes of panels, one for upstage and one for downstage, without having to decrease the amount of space for actor movements on the upper platform. Alan McEwen as sound designer discussed with me the possibilities of using real sound machines that could be operated by the cast during performance scenes. He informed me that we had some in stock that could be used and we agreed to look at these items for approval. Again the potential problem of cost was brought up with regard to the panels, but was informed that no decisions would have to be made until the show was budgeted in one week. 


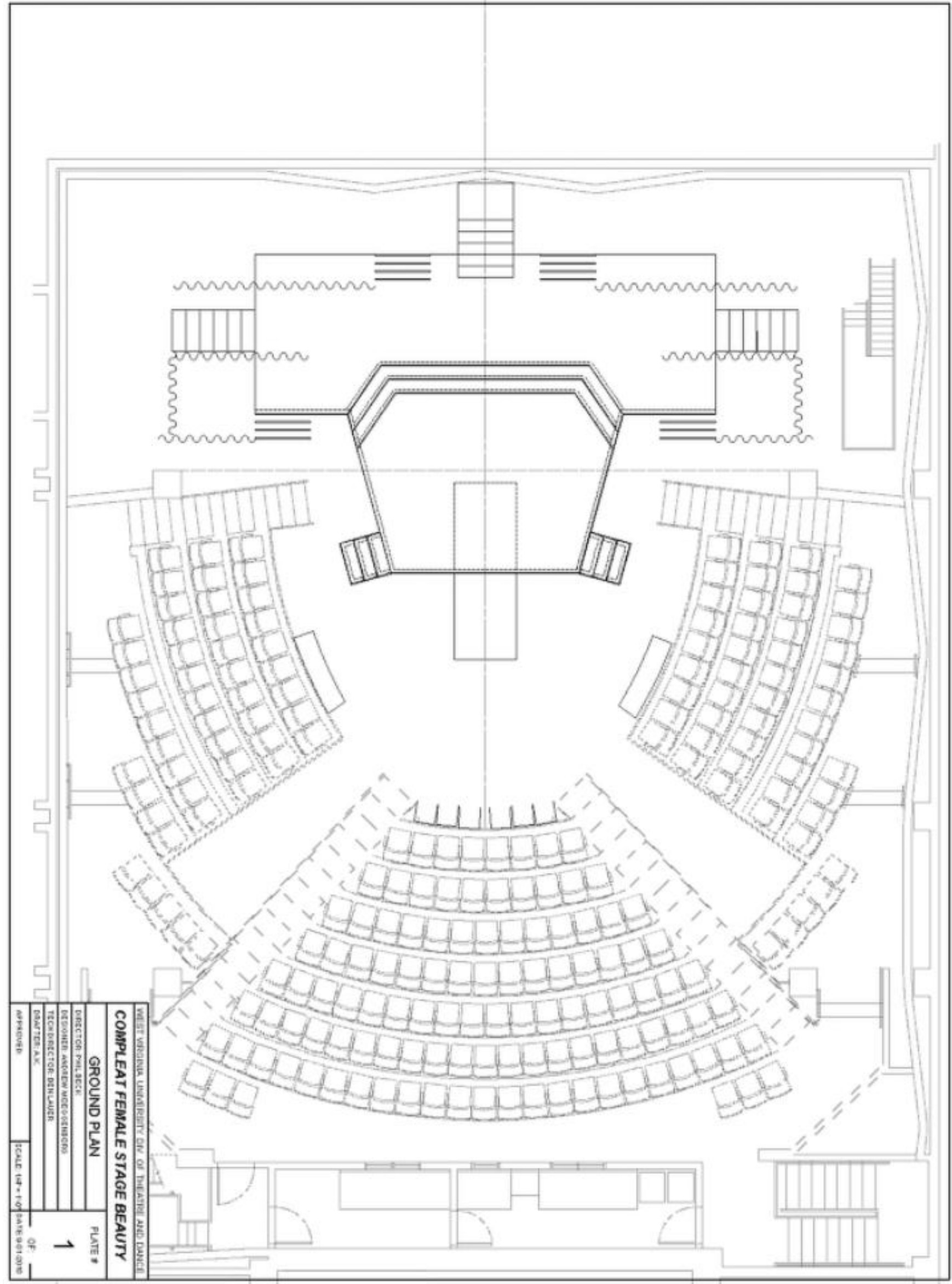

Figure 14

Final Ground Plan Presented to Benjamin Lauer 


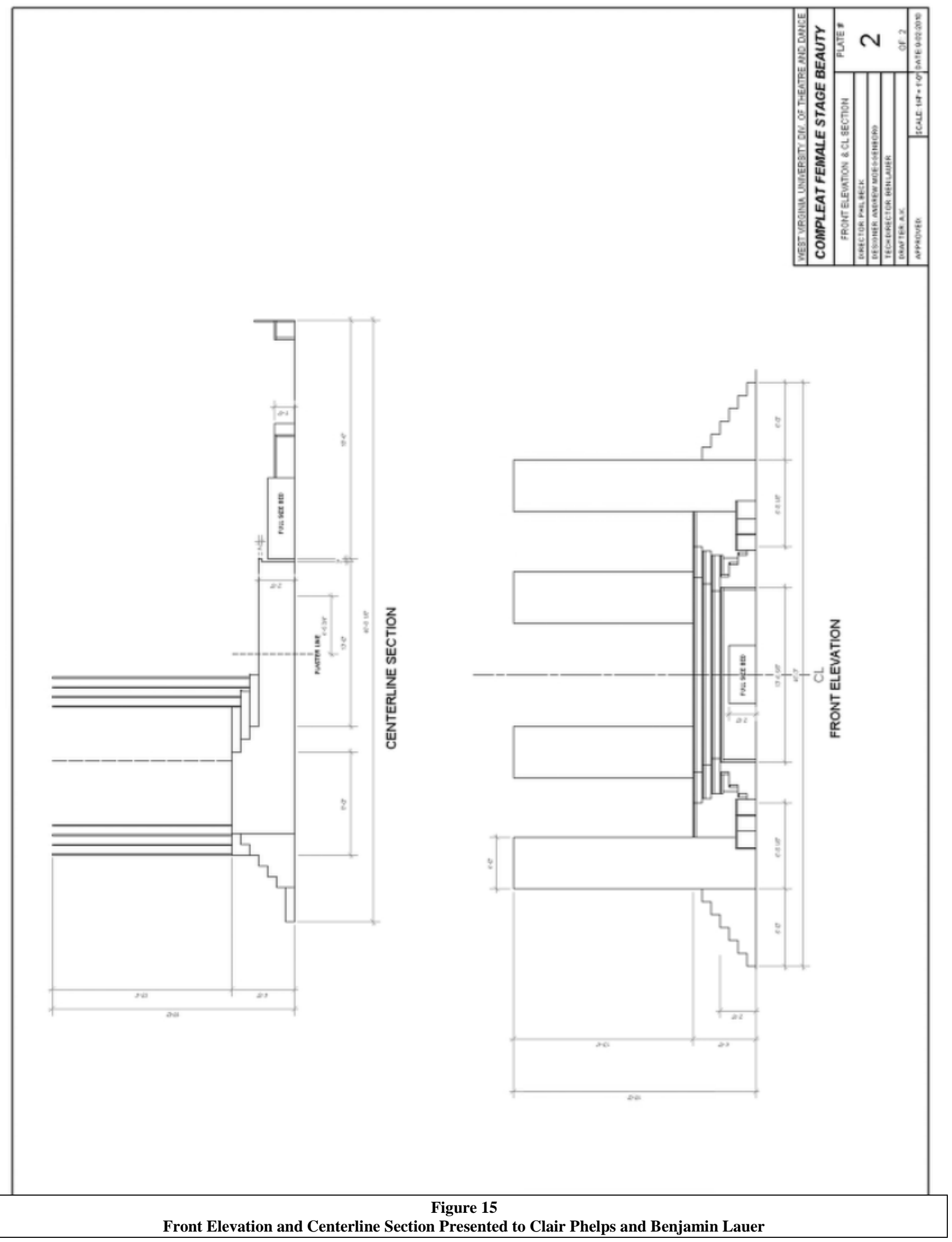




\section{Final Budget Meeting}

Over the next week Ben Lauer came to me with his initial budget estimates. As predicted, the design was over-budget both monetarily and in labor hours. What put the design over budget was the amount of money and time it would take to create four full sets of panels that could each move on and off stage. Further discussions resulted in a solution- to cut a set of panels and make one of the three remaining sets unmoving - the amount of time and resources would be significantly reduced. Though I agreed that his would be the best solution it was still a difficult decision to make and would affect how certain scenes would be staged by Professor Beck. Upon concluding the budget meetings with Ben Lauer I went to Professor Beck to inform him of the decisions that would have to be made. As I had predicted he was unsure where that left the rest of his staging but I had several ideas about utilizing the remaining panels. We concluded that by using the stone walls in the backstage setting as the backdrop for the park and coffee house the effect of being outside of court and a theatre could be achieved. I also spoke with Claire Phelps about how to light the panels so that they could be less noticeable in certain scenes so that the audience would not be confused.

Before the final budget meeting I also spoke with Professor Neuenschwander about possibly finding more money for our budget by utilizing funds not spent on earlier productions, using this method we were able to increase the Stage Beauty budget by $\$ 200$. I also spoke with Professor Klingelhoefer about furniture pieces for the play and we determined that the best approach would be to adapt existing stock chairs and tables to fit the restoration style, saving both time and money that would be needed for the scenery. The final design meeting was short, as many of the changes to scenery had been discussed and decisions made in the days before the meeting. Building the show would begin in two weeks time and dates were set for publicity 
photos as well as cast design presentations. Now it was time to begin work on the scenery itself and to determine how best to replicate my renderings in full scale.

\section{Construction and Painting}

Initial conversations with Benjamin Lauer and Steven Neuenschwander indicated that the most challenging parts of the set to build in full scale would not be the two large platforms but would involve the chariot and pole panels and the sliding bed that was hidden under the first platform. Of these two challenges the greatest would be the chariot and pole panels which would take up much more labor time and budget.

The chariot and pole panels had caused concerns from the very beginning of the process regarding time commitment, labor and equipment needed and they would continue to be a major concern as construction on the set began. The largest challenge associated with the panels was creating the specific track needed to ensure the panels could slide on and off stage without a great effort from the crew or a great deal of noise. In an ideal situation each panel would be constructed on a steel frame and be coating with a combination of lauan and canvas. Very early in the process due to budgetary and labor concerns the construction of the panels needed to change from steel and canvas to a Broadway standard construction of wood framing and lauan coating. Given the fact that each of the twelve panels would have to be identical, construction of these pieces would have to be very tightly regulated by Mr. Lauer, and would take a considerable effort on my part to personally oversee the treatment of each panel. Knowing how unpredictable stocks of lumbers could be, even when being delivered directly from suppliers, I was concerned about two things regarding finishing each of the twelve panels. The first challenge would be ensuring that each panel would be straight and true as well as identical, meaning that the panels would be stiff and not warp out of shape when hung. The second challenge would be to ensure 
that seams between pieces of lauan would be hidden using joint compound, or other means, so that they would not be visible to the audience or cause trouble when the panels had to be painted.

Painting each panel worried me, especially the panels which included painted drapery. Drapery is a difficult effect to achieve and it was absolutely critical to the success of the design that the color of the painted drapes on the panels match the real drapes used as facing on the rest of the scenery. Using my renderings, both Robert Klingelhoefer and I chose appropriate colors that could be used to mix that all-important false drapery; to my dismay the colors we chose to buy did not match the real drapes purchased for the production. Though I was able to use all the other colors that I had chosen after consulting William Winsor and Robert Klingelhoefer, the base color for my drapery was far too light to match the real drapes, after multiple attempts I determined that it was in fact impossible to create the needed colors. Fortunately in our stock scenic paint the Division of Theatre and Dance had an appropriate base color to use for the false drapes, a deep red Rosco brand paint.

Despite finally having the correct colors to paint the panels, I was forced to put them aside as the panels would be completed later in the build process. Instead I concentrated on the marble treatments I had chosen for the main platforms and the wood effect that I had chosen for the stage floor itself. Since Professor Beck and I wished to create a very theatrical looking marble I knew this would itself be a mixed blessing, given that the strain of creating very realistic marble was no longer necessary; creating even theatrical marble can be a difficult undertaking and was one with which I had very little experience. I decided to consult William Winsor, who had created a similar theatrical marble effect for the department's production of Dracula the previous year. The process began with discussions on how to achieve the desired 
theatrical effect, we discussed how to mix the paint and how to apply it over the chosen base coat.

I decided to try a few samples in the shop on my own and see how best to blend the colors together in order to give the impression of marble, my initial attempts were a bit of a

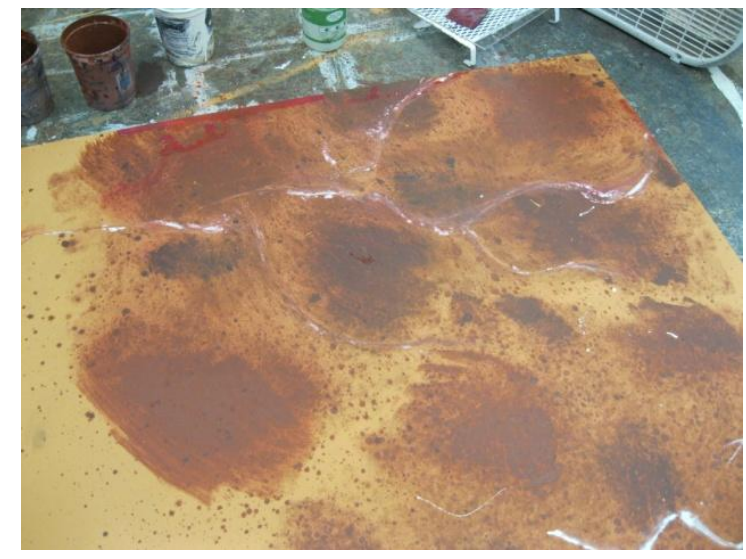

Figure 17

First Attempts at Marble fiasco as I had difficulty achieving the effect. Mr.

Winsor personally came into the shop to observe my first attempts and though he approved of the colors I had mixed for the dark marble, he gave more instruction for blending the colors properly,

roller. I decided to move from the small scale attempts I had initially done to a full size sheet of medium density fiber pine, in order to try the technique on a large scale. Using the techniques discussed with Mr. Winsor I created three larger samples, but was still having difficulty arriving at the desired texture. Mr. Winsor again agreed to help me and after more instruction I felt confident enough to begin painting my second-tier platform, which had been completed in the shop and had its base coat applied.

I decided to paint rapidly as a great deal of water was needed, the result was closer to the desired treatment but was still lighter than I wanted. Upon observing my most recent attempt, Mr. Winsor decided he would personally help paint the upper platform. With his assistance the entire upper platform was

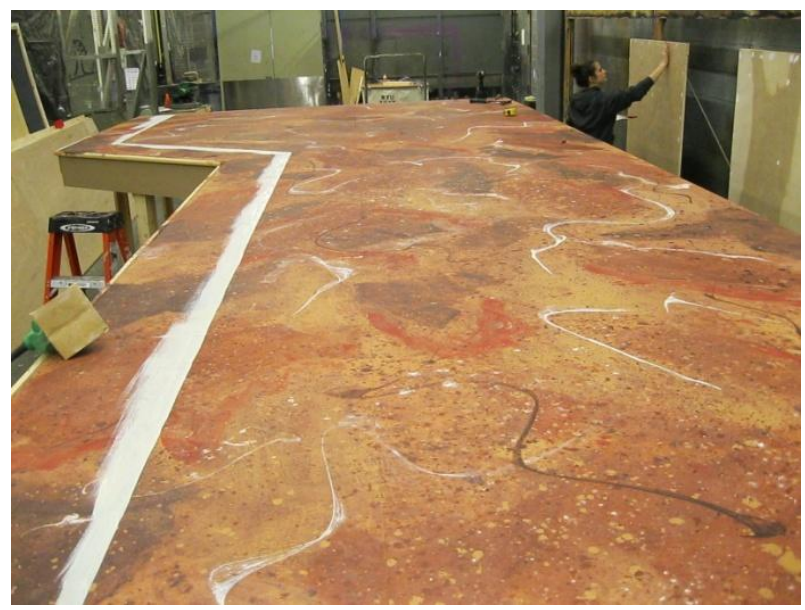

Figure 16 Completed Dark Marble on the Upstage Platform 
painted. The effect matched what was desired and gave me the confidence to carry on the marble

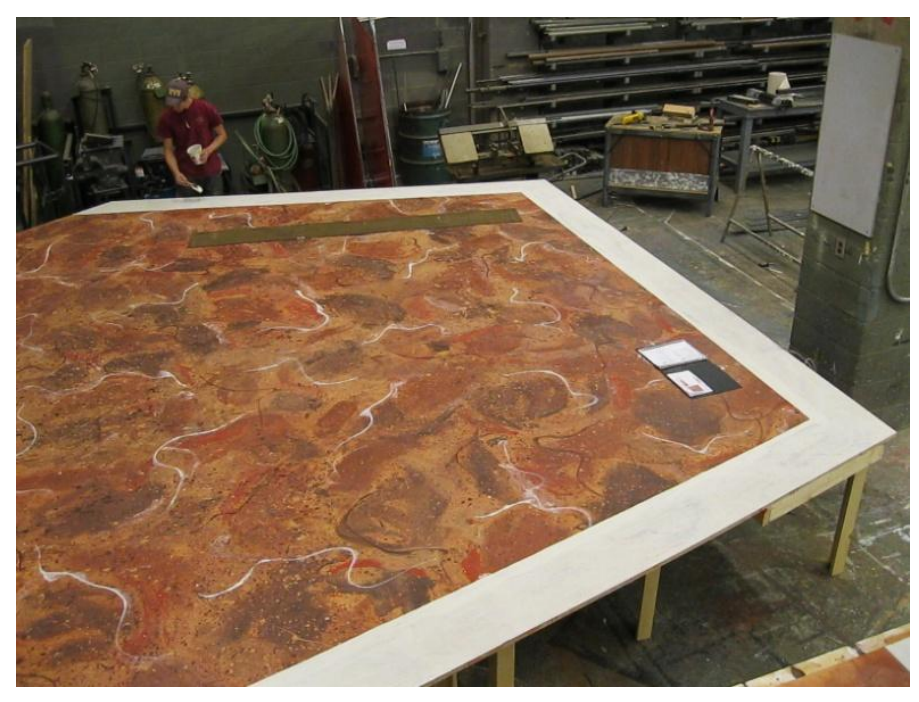

Completed Dark Marble on Downstage Platform

treatment with my students. The second platform was completed the same day during the afternoon lab session, with the help of only one other student. I was very pleased with the effect and the speed with which it was produced. Two days later the border of lighter marble was completed with the help of the same student. After an application of polyurethane the marble treatment for both platforms was complete.

It was at this stage that the chariot and pole panels were ready to receive their final paint treatments. Initially the biggest concern with painting these panels was not the treatment itself but finding space to do the painting. Since six of the twelve panels included painted drapery it was absolutely necessary that these panels be placed flat on the ground as a wet blending technique cannot be accomplished if they are hung vertically on a paint frame. I decided to put four of the twelve panels on the scene shop paint frame, panels depicting the columns that defined the court of Charles II and the stone walls that would depict the backstage and park settings. The technique for creating brick could be accomplished vertically as could elements of the columns. I would paint the drapery panels on the floor first, then once they were completed move them onto the paint frame and complete the remaining elements of the columns and stone once floor space had opened. 
I began by putting a base coat of grey on the four stone panels, then using three shades of grey and a sponge technique created the painted stone. Next I had a lab student with charcoal trace $\mathrm{n}$ the mortar lines. I decided that I would paint in the mortar lines and highlight and
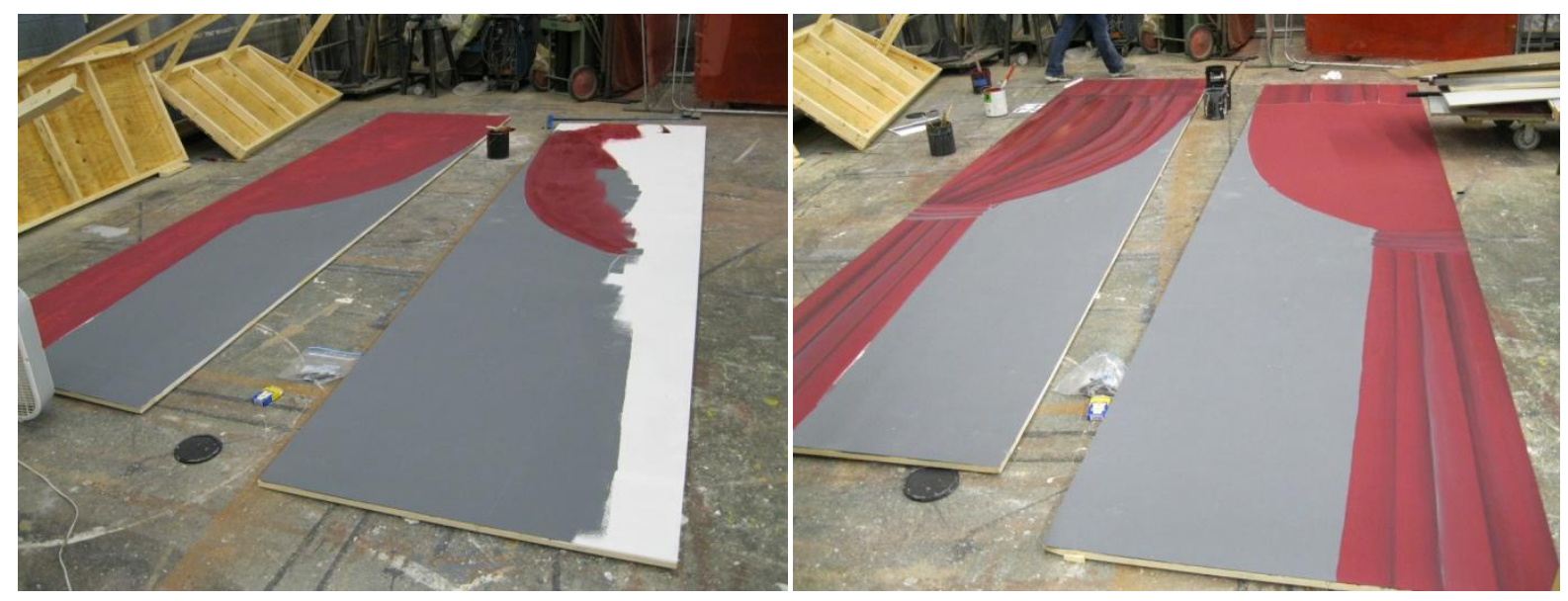

Figure 19

Progress on the Drapery Panels

shadow that evening, but I was also aware that I had not yet started on the drapery, which was the largest concern in dealing with the panels. It was at this point that Sabrina Hykes, the Scenic Shop Foreman volunteered her services to assist in painting the drapery. Using my renderings she drew the outline of all the drapery in chalk then began painting the base colors, after letting the base dry she began chalking out the fabric folds and wet blending. While Ms. Hykes was

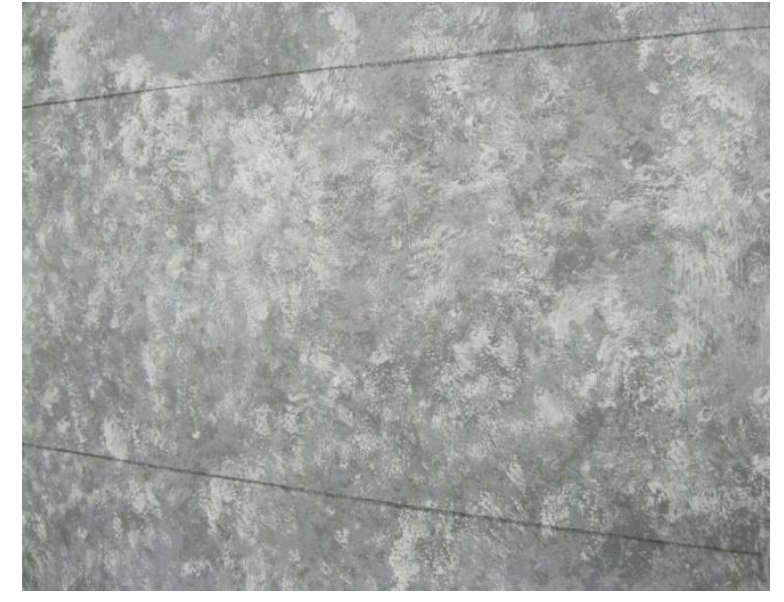

Figure 20 Texture on Stone Panels before Mortar Lines working on the drapery I was painting the mortar lines on the brick columns and adding highlight lines. After a long evening of work, all the break lines in the brick were complete, and two of the four main drapery panels were well on their way to completion. I was very grateful for the help of Ms. Hykes in the beginning of the process but knew 
that as shop foreman she would not be able to see the drapery panels through to completion as she had to supervise construction on the production during lab periods.

Over the following week I stayed late each evening in order to complete the stone panels and to continue work on the drapery panels. I also taught several lab students drapery techniques in order to add highlight or shadow to areas that were not yet complete. Another volunteer was a fellow graduate student in the acting program, Audrey Ahern who stayed for several evenings and was vital in completing the stone and several other elements. By midweek the drapery and the stone panels were finished, which left only the column panels to complete, with the help of lab students during work hours and with the support of Ms.

Ahern and Ms. Hykes in the evenings. During labs starting midweek, lab students prepared the column

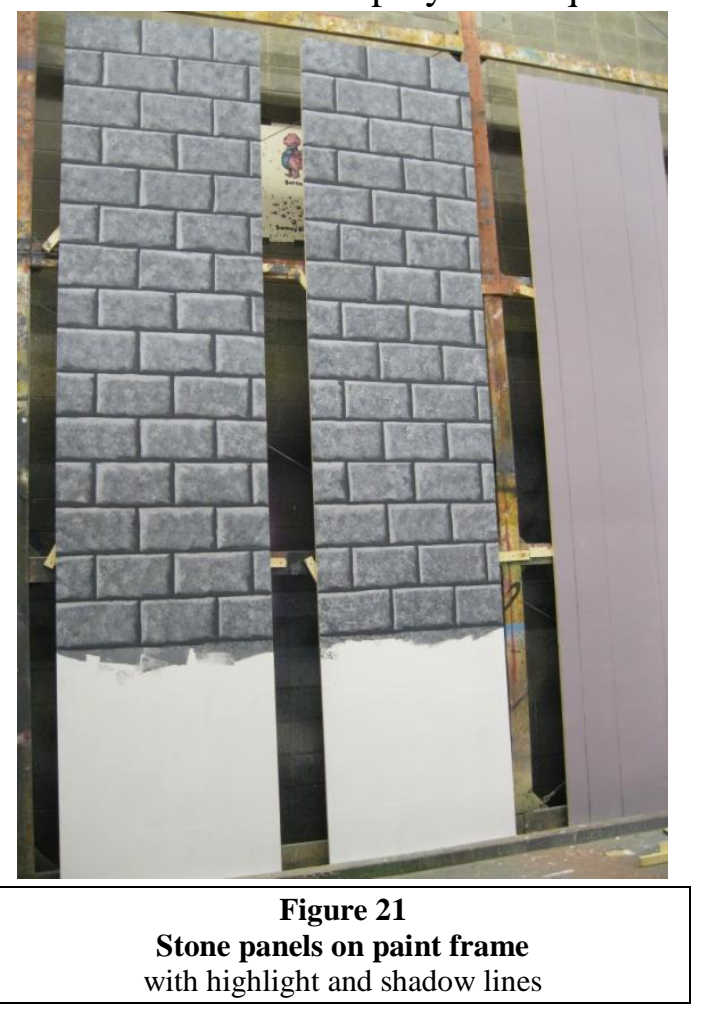
panels by painting in the background color and laying out the main column shapes. I also found the proper column caps using a book on ornament and with the help of Professor Neuenschwander I was able to print out a full size image of the cap, and using a pounce wheel, transfer the outline of the image on to the columns, then hand draw the more specific details. I spent two consecutive evenings adding highlight and shadow to the column caps and bases and adding gold accents.

Most difficult was the massive amount of crown molding located above each column due to the time consuming lining and wet blending techniques necessary to make it appear threedimensional. The final obstacle in the column panels was the fluting that this would require a 
great deal of lining of multiple widths in order to give the impression that the column was a three-dimensional object. Again Ms. Hykes lent her services to add this final detail to the columns. In a full day of work before labs she was able to line two entire panels. That evening, following the advice of Professor Klingelhoefer I added more shadows to some of the existing lines to give each flute more depth, while I was adding final shadows to the outside of the columns Ms. Ahern again came in to assist by lining the remaining columns. The Charles II panels were now complete and I concentrated on the last challenge regarding paint treatments, the hard wood floor.

I had painted wood treatments on scenery before but what made the floor for The

\section{Compleat Female Stage Beauty most difficult}

was how detailed it would need to be in order to look like the teak grain I had chosen. This

specific type of wood has a very fine grain that is very difficult to replicate, though once

treated, it would be a very regal and appropriate treatment for the play. The first step as always

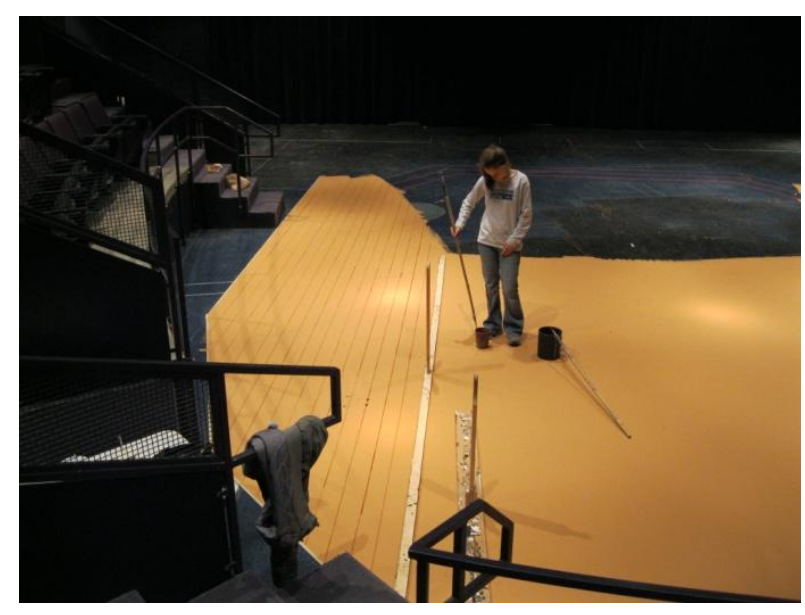
Base color on Floor with plank lines being added was to tape out the shape of the floor on the thrust stage and to paint the base coat on the floor, which I did with the assistance of Ms. Ahern, who also helped me lay in the break lines for the planks of the hard wood. The break lines were painted in two stages when it became apparent that constant rehearsals would damage and peel up paint on the floor, the floor would need to be painted and treated without foot traffic. This was of course a difficult decision to make as it would deprive the cast of the opportunity to rehearse on the set. Fortunately with the support of Mr. Beck I was given three full afternoons and evenings in the space to complete the floor. 
The first evening of work saw the patching of the base coat followed by the completion of lining. I decided that it would take at least two washes of wood tone paint in order to achieve the multi-dimensional look of teak wood. I mixed the first color and after testing it on a small sample of base in the shop I decided to go ahead and apply it to the floor. I felt the effect looked very good, and decided to show it to Professor Winsor and Professor Klingelhoefer the next day. After showing the results of the previous evening to both men I was advised to add another base coat before applying the polyurethane to the floor. I mixed a darker color this time and layered it
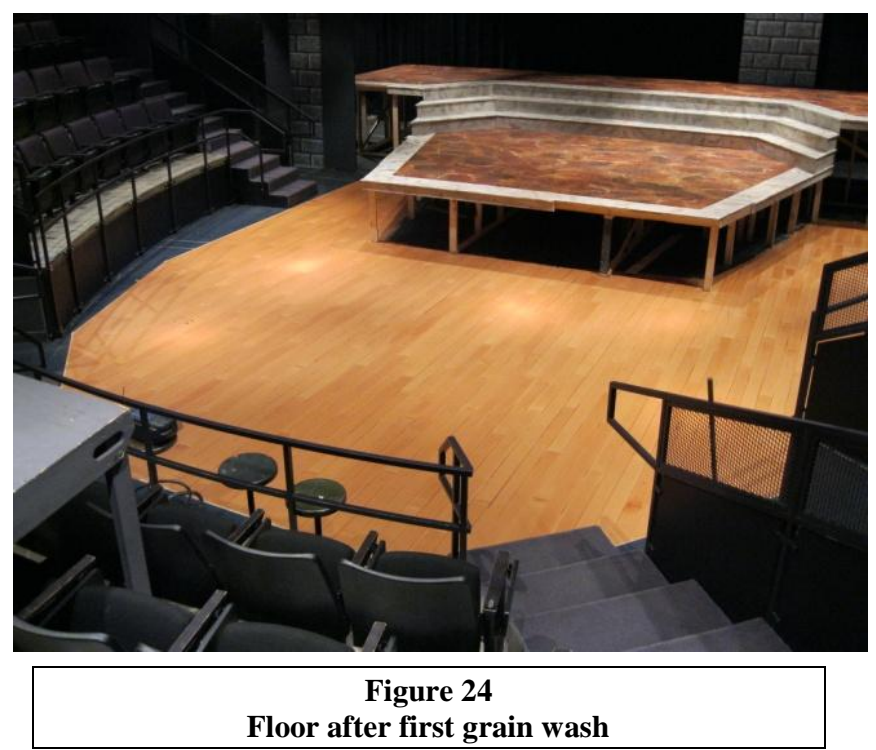

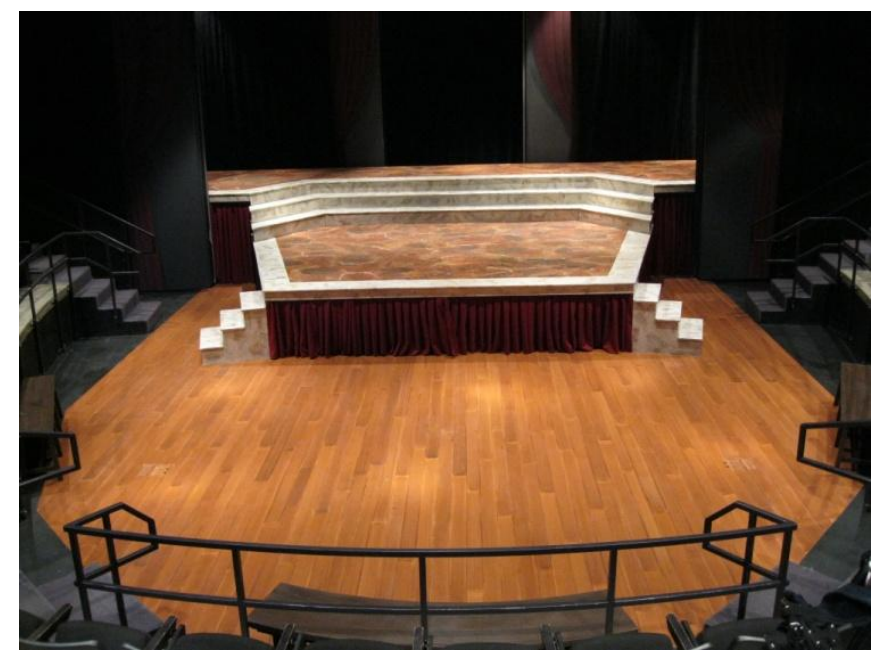

Figure 23 Completed Floor with polyurethane top coat

over my previous wash. The result was precisely what I wanted to achieve. The following evening, the last of my time allotted by Professor Beck, using the same brushes as I had used on the washes, to better match the grain in the planks, I applied three coats of polyurethane to the floor. Not only was the floor now complete but also safe from being damaged due to foot traffic, though this would remain a constant concern as technical rehearsals began.

\section{$\underline{\text { Load In }}$}

For the most part the scenery was moved into the space without incident, as the largest elements had already been assembled in the scene shop for painting. The greatest challenge would be installing the panels and their tracking into the space. Mr. Lauer supervised that project 
and was extremely efficient in putting each panel into place. It was discovered that the tracks and carriers that had been manufactured in our shop allowed for each panel to be moved by one crew member with very little effort, in a very smooth, and most importantly, silent motion. The only real concern in dealing with the panels once they were in the space dealt with sightlines. Though I had placed a great deal of masking on my ground plan for the scenery to solve this problem, it was discovered that when the front panels were in their offstage position there was a direct line of sight to the escape stairs backstage left and right. It was Mr. Lauer and Professor Neuenschwander that solved the problem by taking stock flats and installing them on the downstage side of both staircases. This would hide them almost completely from the audiences view, save for a few seats on the most extreme edges of the space. This however, was not the last challenge that would result from the panels.

It was discovered that the panels did not stack on top of one another nearly as neatly as they had in my renderings and models. The distance between them made necessary by the tracking in the ceiling meant that panels that were supposed to be hidden from view were too often visible. This was especially a concern when the first panel was in place without the second stacked

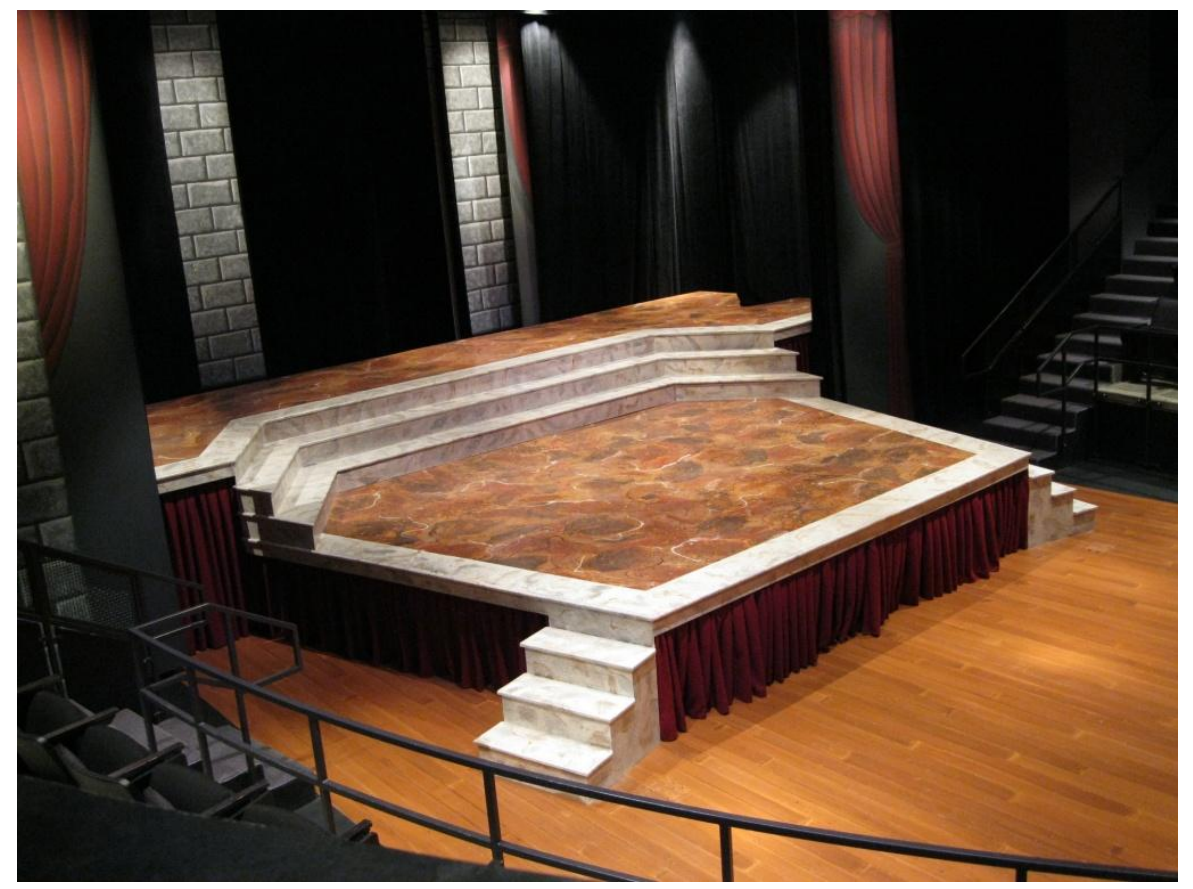

Figure 25 Completed set with fabric reveals visible on panels 
immediately behind. There was a space of roughly three feet between these panels, that from the extreme seats in the audience made half of the third set of panels appear uncovered. I had accounted for this early on but not the extreme that I now saw. In order to solve this problem I devised a simple solution: add fabric to the onstage edges of each panel that would extend back nearly to the panel behind it, essentially thickening each panel. Instead of having over half the rear panels visible, now only a few inches were. In addition I informed the stage manager that during shifts in which the very front set of panels had to come on, the second set would have to be moved onstage as well. This eliminated the concern of seeing the third set.

In addition to the sightline problems created by installing the panels there was also the problem that I had feared from the beginning; warping. Even with the large amount of framing in each panel, the humidity in the space and the quality of lumber used on them warped each panel. Initially I feared that something drastic would need to be done in order to make each panel look more rigid, however after adding the fabric strips on the onstage side of the panels, and observing them from different places around the space I determined that the problem was not visible enough to spend more time on.

One element of the set that I was extremely pleased to see was the sliding bed that could be slid out from underneath the first platform. Mr. Lauer had done a fine job making a bed that
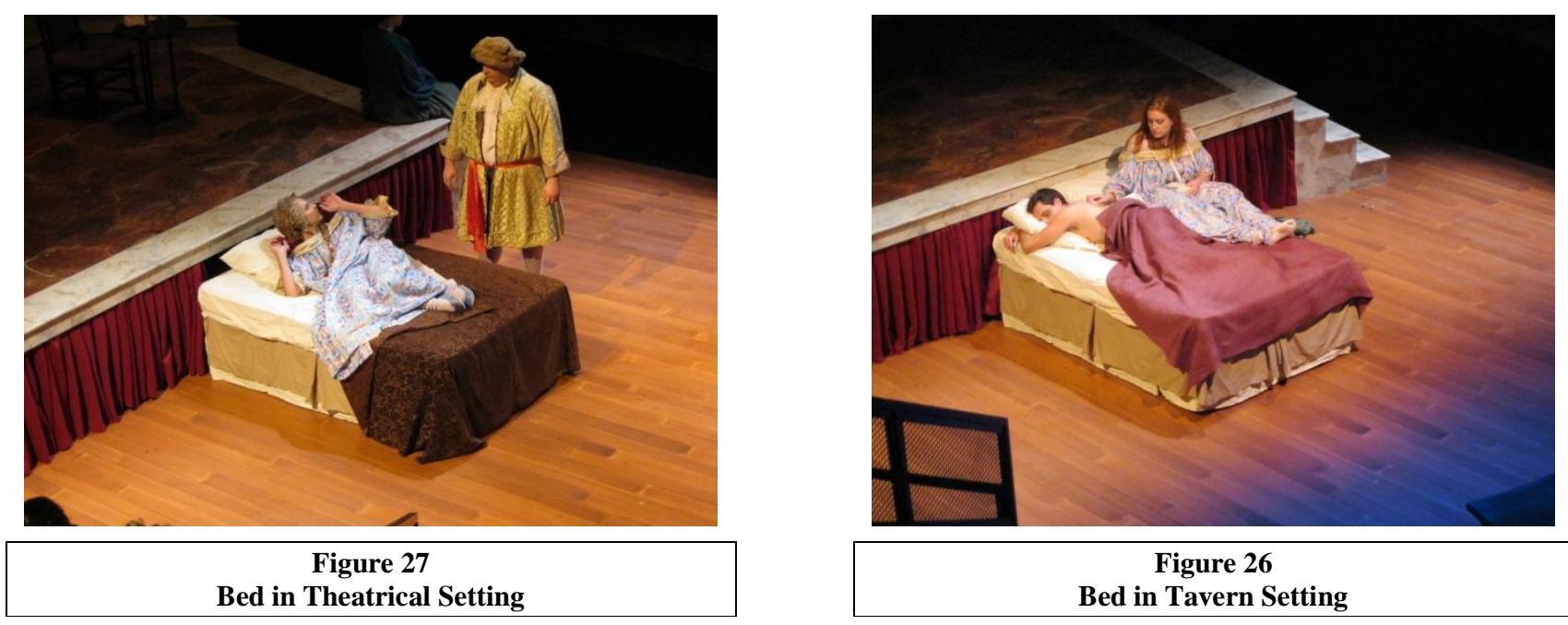

Figure 26 Bed in Tavern Setting 
would be easy to operate and able to lock in place so that the action that took place on the bed would not force it to move out of position. Mr. Klingelhoefer and I also solved the problem of how to make the same bed appear to be in two different locations over the course of the play by adding removable top blankets, and separate pillows for the two settings that could be changed by a crewmember quickly instead of having to switch out literally every piece of bedding in view of the audience.

Professor Klingelhoefer also did a fine job of adapting existing furniture into pieces that

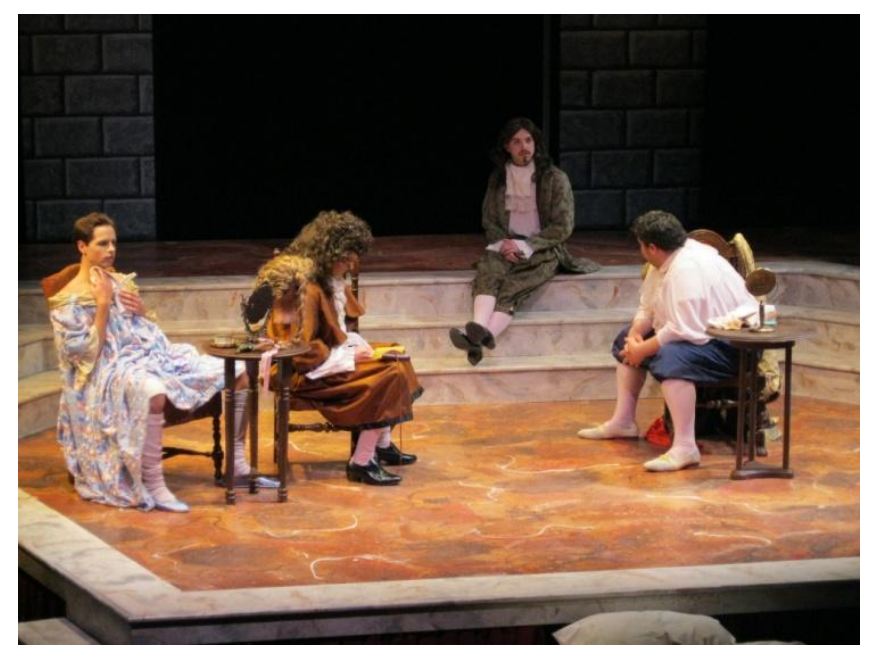

Figure 28

Furniture in the backstage setting would better suit the Restoration period.

Making use of fine Victorian furniture that was available in stock, he adapted them by re upholstering various pieces, especially the chairs for the dressing room scenes and by finding hand props that fit the time period, specifically hand mirrors and letters. In two scenes actors had to remove blackface makeup onstage in view of the audience so period cold cream containers were needed, after trying to adapt modern containers, tins matching the time period were found to be used on stage.

One unexpected challenge that came up as a result of additional meetings with Professor

Neuenschwander was the third bench that was initially going to sit at the tip of the thrust to allow characters to watch

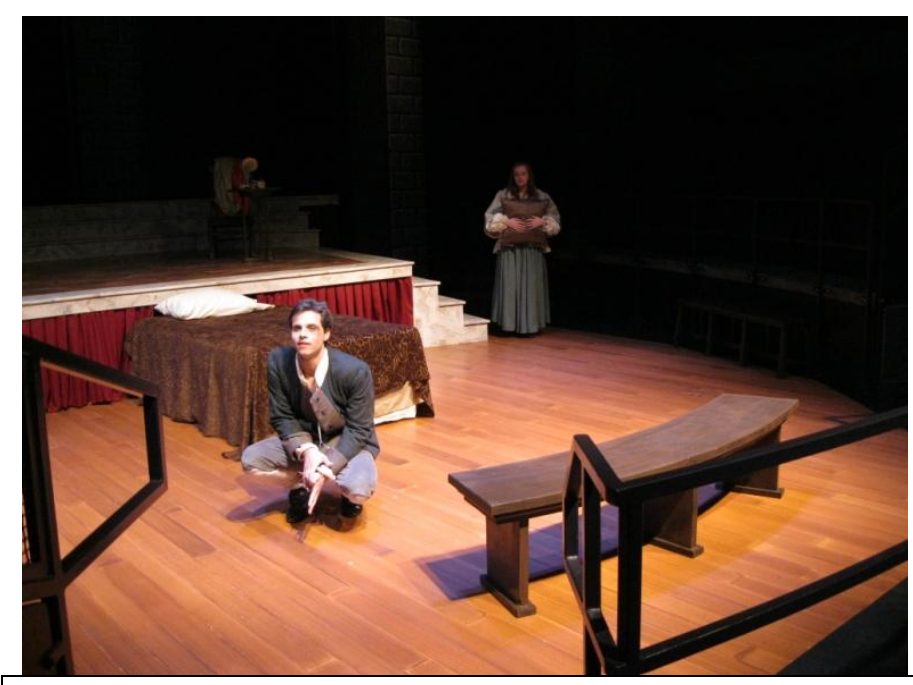

Figure 29 Third bench when set for handicapped seating 
the action on stage. This was an idea that was discussed early on with Professor Beck but had been discarded due to safety concerns and handicapped seating arrangements. I discovered that in rehearsals Professor Beck had been using a third bench I had two concerns with a third bench: first, I had not yet gone with Professor Klingelhoefer to find an additional bench and second, I feared in a handicapped seating situation, the final climactic scene would be hidden from most of the audience. Though I expressed these concerns to Mr. Lauer and Professor Beck, we determined that there was no other configuration that would suit the purpose, and all involved would just have to take the risk that during productions there would be no call for handicapped seating. Though I still had reservations about the third bench, I was able to pull and paint it without incident in time for the first full rehearsals in the space.

\section{$\underline{\text { Technical Rehearsals }}$}

Crew view was the first full rehearsal before the production went into technical and dress rehearsals. This would be the first time the crew and production staff would get to see the play performed on the actual set, though the actors would not be in costumes. The play was well received by the crew but on the technical side I did have a few concerns about pieces of scenery and props. In the plays opening scene several actors use sound effect machines that had been found in the department's stock, the metal thunder sheet was far too reflective and modern, and the fabric on the wind machine was also highly reflective. I made notes to add paint treatments to both the wind machine and thunder sheet as well as the steel bed frame, which was too visible beneath the mattress. Another problem with the bed occurred when action took place on top of it, the mattress slid on top of its frame. A solution to this problem was proposed by Mr. Lauer who agreed to secure the mattress to the frame via stitching. In addition to the mattress sliding on its 
frame, during this rehearsal the locks were not put in place to secure the bed frame which also shifted uncontrollably during scenes of action.

The next day I sent many lab students to work, painting the bed frame and applying spray paint to the thunder sheet in order to make it look more weathered. I had to patch two areas in the floor paint that were peeled up from furniture and, Professor Klingelhoefer also applied padding to the bottom of furniture pieces to avoid any more blemishes to the main stage floor. I decided to wait until the first dress rehearsal to see what effect period shoes would have on the main stage floor. Though three coats of polyurethane had been put on the floor it was still a concern.

On November 12, 2010 the first technical rehearsal was held with the crew and actors. This was to determine light and shift cues without actors in costume. It was during this rehearsal that the panels were shifted for the first time. Immediately challenges arose, because there were four crew members operating four separate sets of panels, so coordinating movements proved to be difficult. Other problems dealt with how crew were to enter the space without running into actors exiting, especially when shifting scenery on the first platform. It was determined that a crew member placed underneath the first platform would need to assist actors in moving the bed, as the frame was very heavy and difficult to hold on to from its downstage edge. It was decided that for an hour before the next day's technical rehearsal, the crew would run each scene shift in order to better synchronize the movement of panels and furniture pieces.

The second and final technical rehearsal was held on November 13th and began with the aforementioned shift rehearsal. Even with practice the panel movers still had problems coordinating their shifts. I personally timed and assisted in cueing each scene shift, attempting to have the panels move on a three count. After an hour the movements appeared to become more synchronized, but would take a few more rehearsals of practice. It was during this second 
technical rehearsal that I noticed the lack of light on the panels, I mentioned this concern to Ms. Phelps who informed me that she would attempt to put more light on them. Other concerns that were remedied during the second technical rehearsal regarded the timing of certain cues, as several times crew members would enter the space before the lights had gone down.

\section{Dress Rehearsals}

November 14, 2010 was the first dress rehearsal held for the production. Though the scene shifts had been practiced, the set had not yet proven its effectiveness with the inclusion of actors in full costume and makeup. The most persistent concerns during this rehearsal concerned crew being too visible during scenic shifts. I spoke with Ms. Phelps and the stage manager Krista Whites to add longer transition cues in order to better hide the crew. There were a few incidents that displayed the crews lack of experience in shifting the scenery, especially when moving the bed, and closing the facing curtains behind it.

The most distressing problem that occurred in this first dress rehearsal concerned the shoes worn by the actors, specifically their impact on the stage floor. At the intermission I walked the main stage floor and determined that the crew would have to inspect the floor for scuff marks each evening. Scuff marks could be cleaned off but large gouges in the floor could not, one of which occurred in the first act when an actor slipped and put a two foot black scratch in the stage floor. I tried the next day to clean the mark but had no choice but to re-paint six floor boards beginning with the base color, then reapplying both washes and three coats of polyurethane. Fortunately repainting that section blended extremely well with the rest of the floor, but I still raised my concerns to Hannah Wold that it would be a very large task to completely repaint large sections of the floor after each performance. Ms. Wold decided that a 
solution to the problem would be to apply different coating to the soles of the shoes worn by the cast that would have less potential to make irreparable marks.

Having seemingly solved remaining problems with the scenery, I was more confident as the second dress rehearsal was held on November 15, 2010. The scenic shifts had improved a great deal since the first technical rehearsal, though on at least one occasion when the panels were shifted to their onstage position they were slammed onto their stopping blocks making a very audible sound. Furthermore, I requested that one more transition be added in Act I to allow for a longer shift. All other light cues had gotten much cleaner and more efficient. Overall the show had improved significantly and was nearly ready to open.

The final dress rehearsal was held on November 16, 2010 and for the first time the issue of the downstage bench was addressed. Thus far the bench had been placed in its furthest downstage position but for this rehearsal Mr. Beck and I decided that the cast would need to rehearse just once as if handicapped seating was needed. This caused a great deal of stress as sightlines, particularly in the final scene, proved to be unacceptable as the main section of the audience would be almost completely cut off from the onstage action when characters sat on the bench. However, there was little that could be done at this stage in the performance to remedy the problem, since no handicapped seating had been requested for any performance. The first audience that would see the show would be students at a preview performance to be given the following evening.

\section{Preview Performance}

The Student preview performance, before the official opening on November 18, 2010 would be the first time the play would be performed before an audience. It was this preview that reiterated the old theatrical adage that "a bad dress rehearsal leads to a great opening night" but 
more specifically reiterated Murphy's law "Anything that can go wrong, will go wrong." During this performance Hannah Wold, Claire Phelps, Benjamin Lauer and I sat in the audience to gauge audience reactions and to better spot any potential problems to be solved before opening.

My early fears regarding the content of the script were confirmed with the young student audience, specifically scenes involving sexual interactions between Kynaston and his lover Lord Villiers. Many audience members actually covered their faces or vocalized their discomfort and the atmosphere in the space could be described, as tense, to blatantly disrespectful. Given the audiences attitude to the content of the script it was very important that the production run seamlessly, unfortunately this was not the case.

The meticulous practice that the crew had undergone in shifting the panels did not succeed in this performance since they were almost universally out of synchronization and several of the cues were called late. At one point the stage crew was extremely late in striking furniture from the downstage platform, and in the final scene the bed was not locked in place, causing it to shift dangerously. After the performance the designers met with Krista Whites to discuss late cues and shifts, and it was agreed that another rehearsal for shifting the chariot and pole panels would be necessary before the first performance. Upon completing this note session, I inspected the stage floor and did not find any more scratches or blemishes. There was no remaining work necessary on any other scenic element so the production was ready to open on November 18th.

\section{Evaluation}

I was extremely proud of the finished design of The Compleat Female Stage Beauty, but as with any production, upon further reflection I know there were certain elements of both my 
process and execution that could have better suited the design. Most of these criticisms were brought to my attention by self reflection and from the comments of others.

The most visible element of the scenery that could have been improved were the all important chariot and pole panels. I still believe that switching from four sets to three was extremely detrimental to the overall design, as some of the instances when different panel sets had to be mixed and matched did not always suit every scene. Specifically in scenes taking place in the Cockpit Tavern setting, the upstage stone were not always visible and the downstage panels for the backstage setting did not create the atmosphere of a tavern or an inn. Since we could afford only two moving sets of panels, I feel that if the final set of panels could have been shrouded in drapery for different scenes, especially in the park and tavern settings, this would have made the stage appear more open as well as dark and foreboding.

With regard to treatments on the panels I felt that some of my treatments should have been improved. For instance the drapery panels looked very good under shop lights but under stage lights the grey background behind the red curtains was far darker than I had intended and in some scenes lost almost all their depth. The panels for the backstage setting, the stone walls, looked very good under shop lights but had the opposite problem of the drapery panels and often appeared too bright on stage. I feel that if I were able to re-paint the panels I would have used far darker shades of grey in order to eliminate this problem. As for the panels that displayed the court of Charles II, I was happy with the way the columns, caps and trim looked under lighting. However, the color I had chosen for the background, a deep purple was also far brighter than I had intended when put under stage lights. Another treatment I regretted not putting on the court panels was some kind of spatter wash, in order to make the background color look less flat and brightly colored. 
During the design and painting process I wish that I had been in better communication with Claire Phelps the lighting designer, as we could have more thoroughly discussed visibility for different scenes before the rehearsal period. Her input on my paint treatments, especially on the panels, would have been helpful in completing different scenic elements. I also regret that I did not communicate better with Alan McEwen the sound designer whose wind machine and thunder sheet were used in the show as hand props. These props were used by the cast in the very first scene, (as discussed in early meetings) but they were not used again after that scene I feel that other scenes may have been able to include them but I did not voice my opinions on the matter for fear of stepping on the responsibilities of other designers.

A third aspect of the production that could have been better executed regarded furniture. Though I used three benches on all on the downstage edges of the stage, none fit particularly well within the restoration time period. For fear of spending too much money I decided to pull existing benches from stock and repaint them. If I had done more research into furniture of the time period I would have constructed my own benches so that each would have been uniform and fit the period. I used the same strategy for choosing tables for the makeup room settings, one table looked very accurate, the other had been a stock table that was originally constructed in a 1930s style, and though they were only used twice I felt that this was an area that I could have exerted more effort.

\section{Conclusion}

As with any production, I feel that I have learned a great deal from my experiences on The Compleat Female Stage Beauty. I believe that through working with fellow graduate students on the production I gained a valuable insight into communicating with others on the design team. I also found that Professor Beck was an enjoyable director to design for, the 
discussions we had pertaining to the set were invaluable to the overall process and I feel that the design was better for it.

On this production I also feel that I learned a great deal from members of the Division of Theatre and Dance faculty who offered their services for this production. There is not a doubt in my mind that without the assistance of Associate Dean William Winsor and Professor James Held, painting the scenery would never have been so efficient nor the result so desireable. Overall the design process for this production went very well, I believe that I have improved both as a designer and as a painter a great deal since my first Division of Theatre and Dance production two years ago. 


\section{Works Cited}

Donovan, Fiona. Rubens and England. New Haven: CT., 2004. Print.

Harris, Brice, ed. Restoration Plays. New York: Random House, 1953. Print.

Juracek, Judy A. Surfaces: Visual Research for Artists, Architects, and Designers. New York: W.W. Norton, 1996. Print.

Lawrence, Robert Gilford. Restoration Plays. London: J.M. Dent, 1994. Print.

Meyer, Franz Sales. Handbook of Ornament: a Grammar of Art Industrial and Architectural Designing in All Its Branches for Practical as Well as Theoretical Use. Mineola, NY: Dover Publications, 1974. Print.

Nagler, A. M. A Source Book in Theatrical History. Mineola: Dover Publications, 1952. Print.

Pecktal, Lynn. Designing and Drawing for the Theatre. New York: McGraw-Hill, 1995. Print.

Schama, Simon. "The British Wars." A History of Britain. BBC. 08 May 2001. Television. 


\section{Gallery of Research Images}
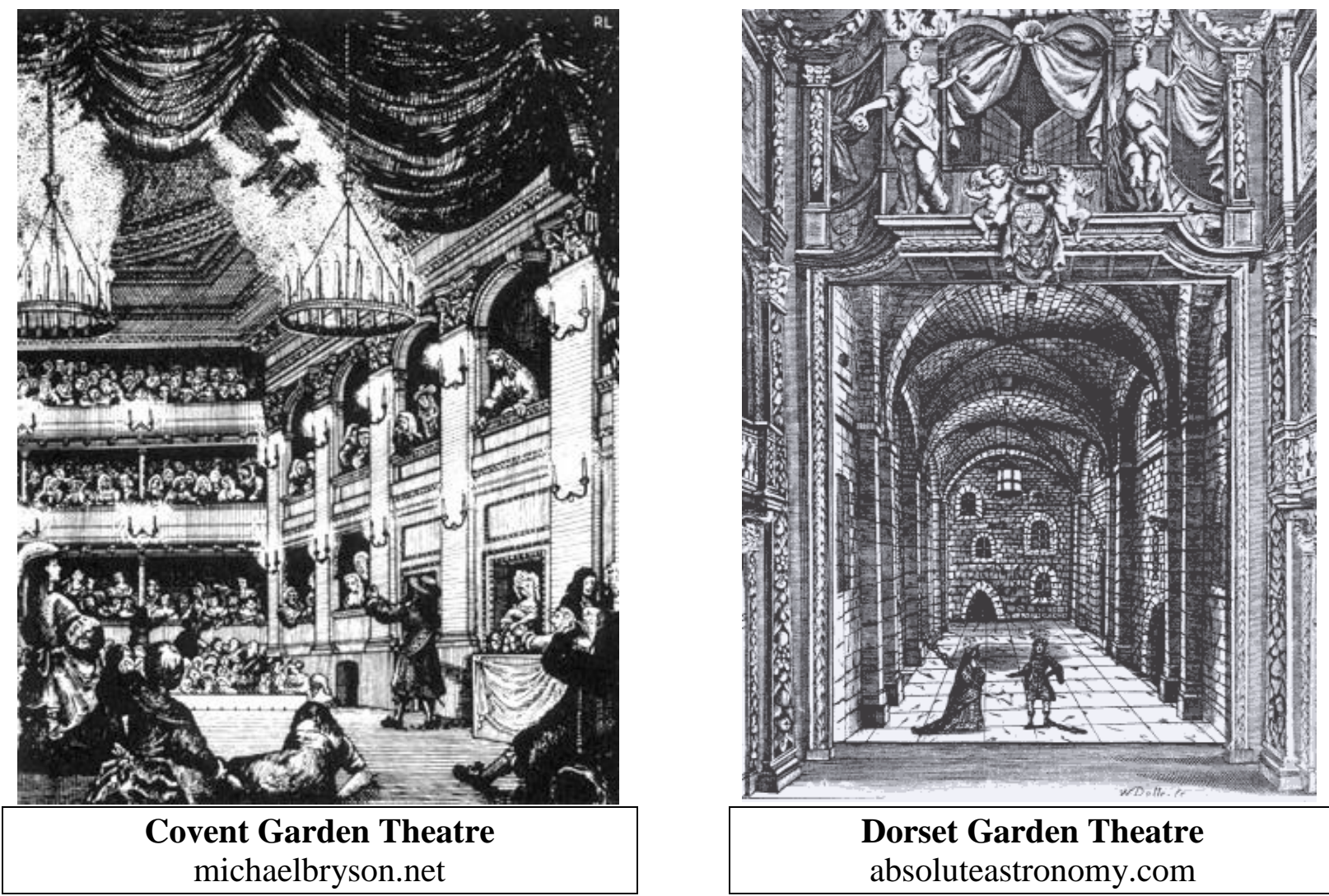

\section{Dorset Garden Theatre \\ absoluteastronomy.com}

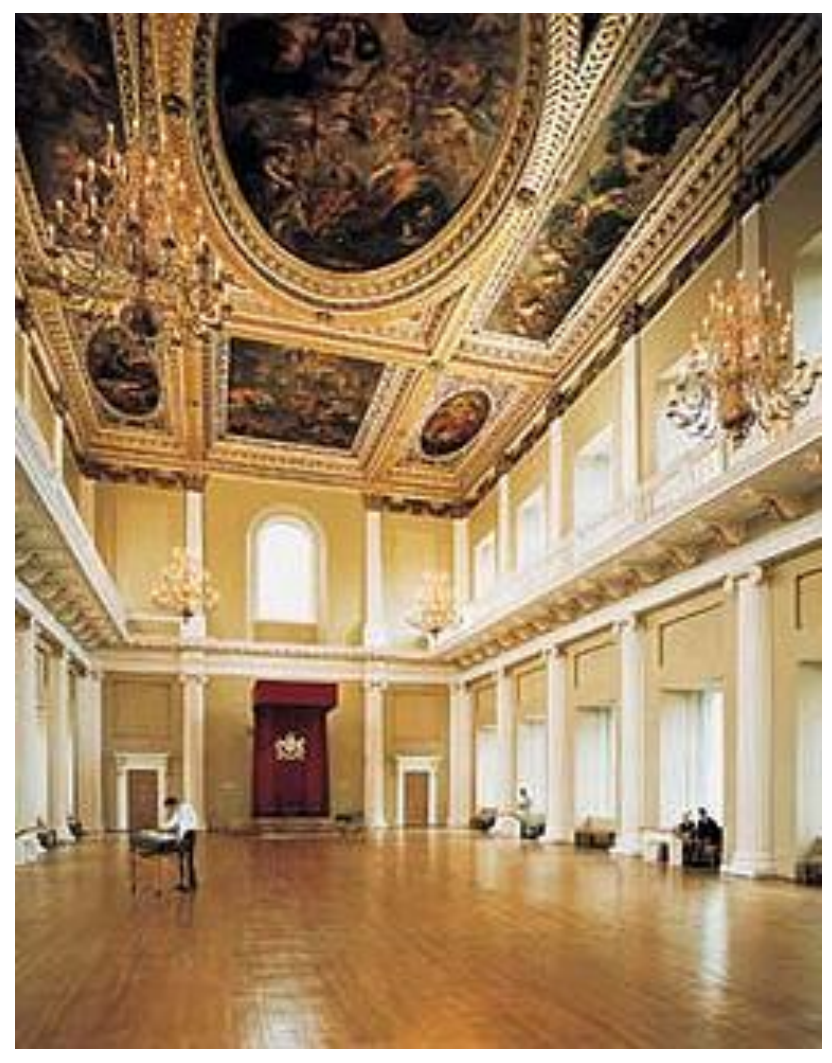

Banqueting House at Whitehall Interior www.londonpass.com/attBanquetingHouse.asp

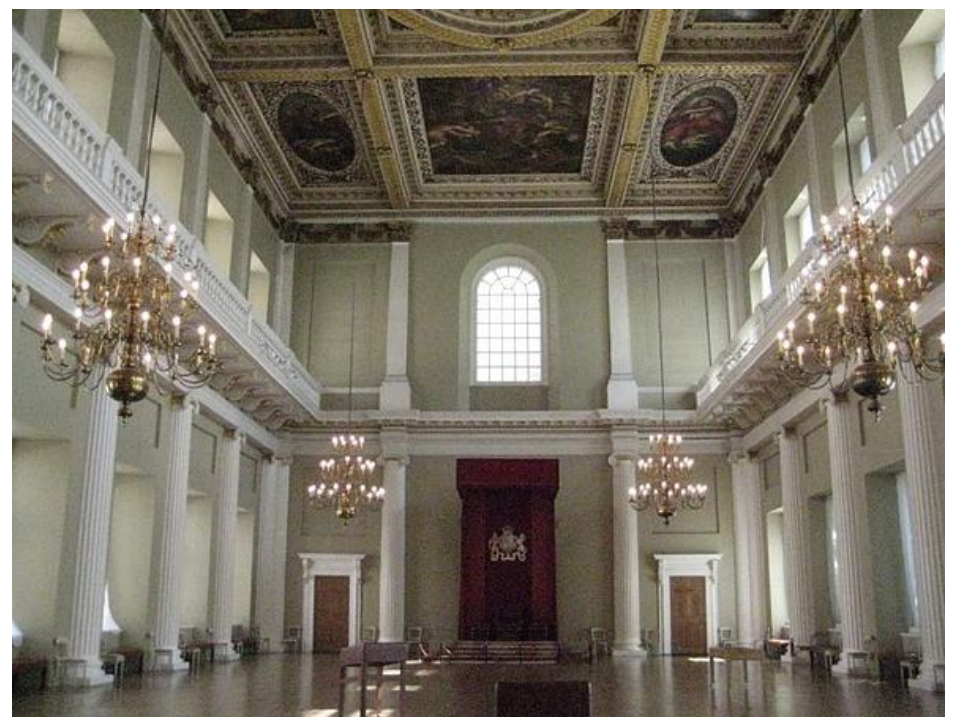

Banqueting House at Whitehall Interior ondontownsummer2009.blogspot.com 

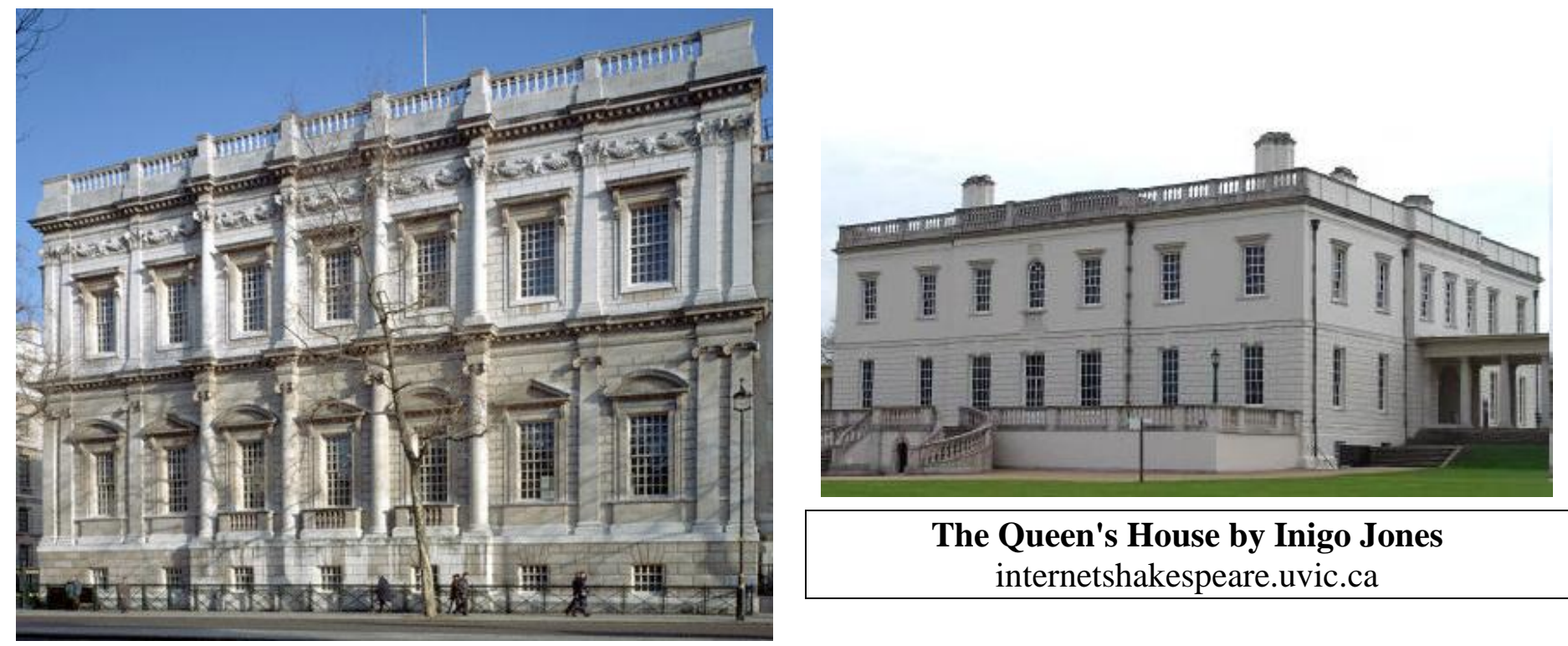

The Queen's House by Inigo Jones internetshakespeare.uvic.ca

30 Banqueting House Exterior

corbisimages.com

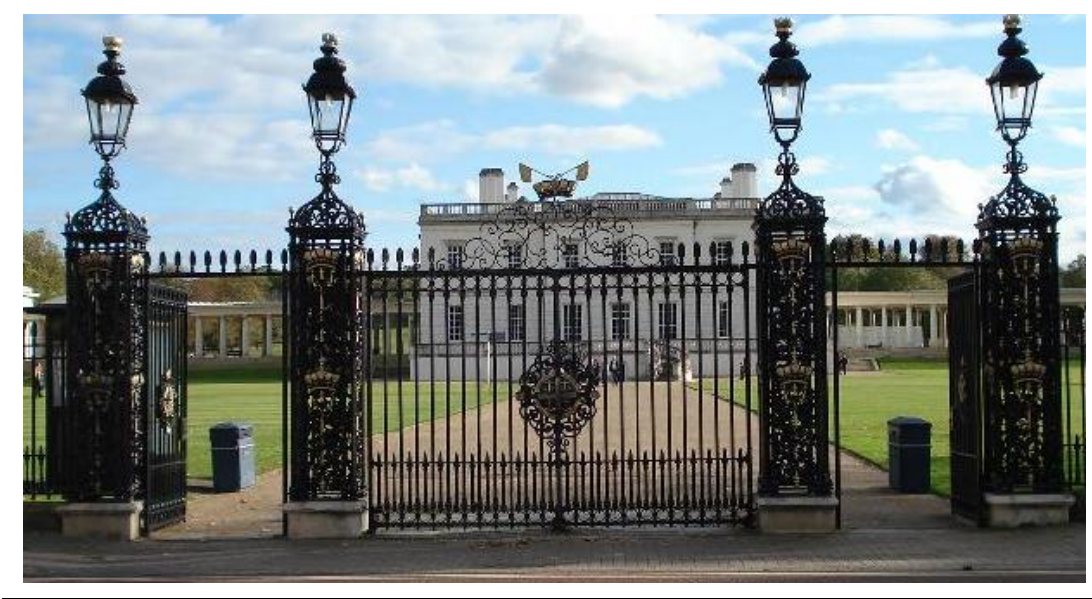

Gate of the Queen's House portfolio.du.edu

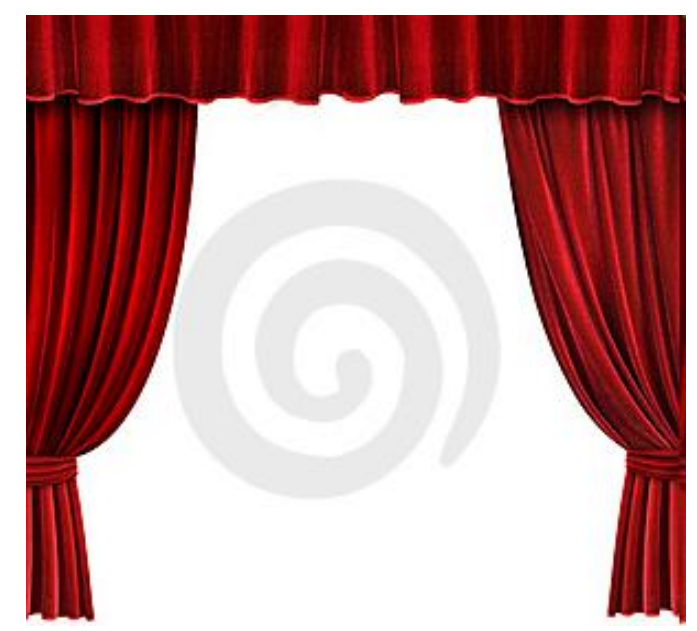

Theatre Drapery

http://thumbs.dreamstime.com

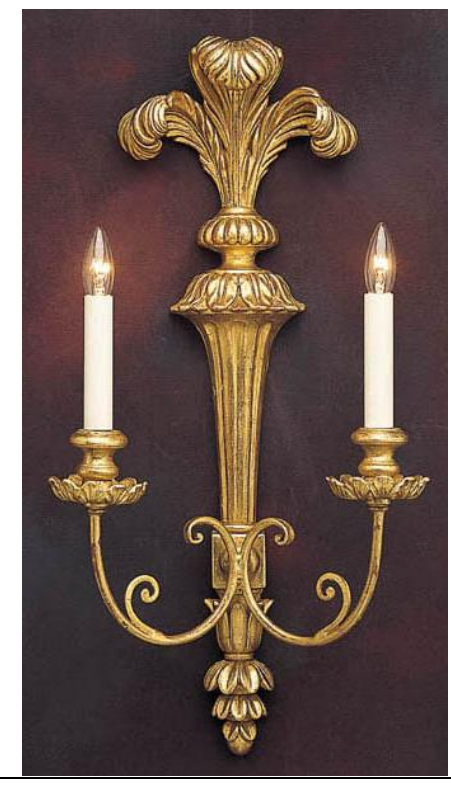

Restoration Wall Sconce invitinghome.com

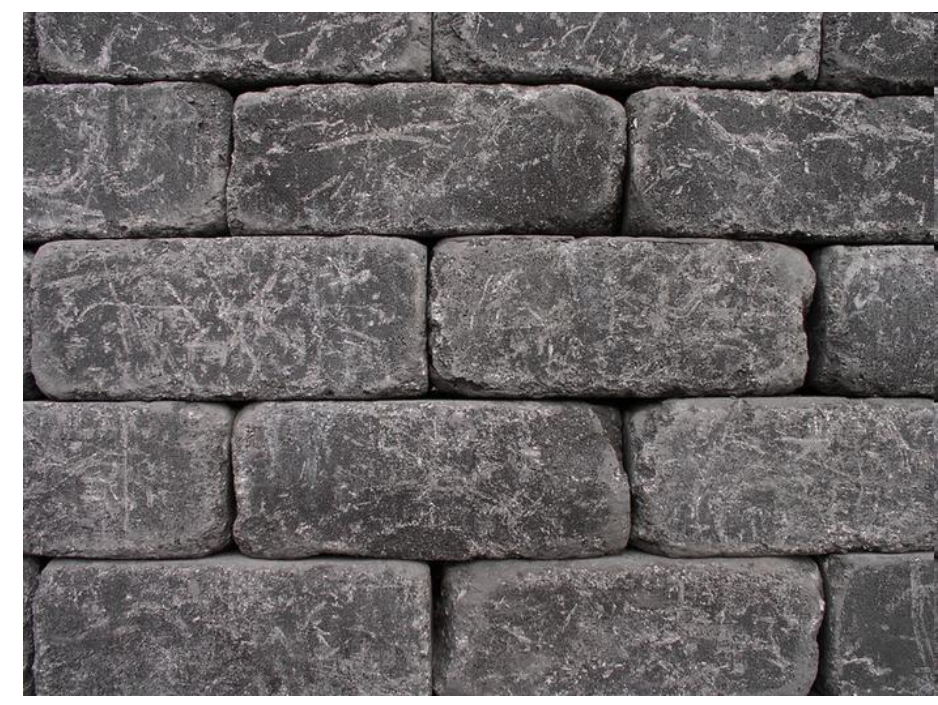

